\title{
Synthesis, Structure and Solution Studies on Mixed Aryl/Alkyl Lithium Zincates
}

Andrew J. Roberts, Alan R. Kennedy, Ross McLellan, Stuart D. Robertson* and Eva Hevia*

WestCHEM, Department of Pure and Applied Chemistry, University of Strathclyde, Glasgow, UK, G1 1XL.

stuart.d.robertson@strath.ac.uk; eva.hevia@strath.ac.uk

http://www.strath.ac.uk/staff/robertsonstuartdr/; http://evaheviagroup.com/index.html

\section{$\underline{\text { Abstract }}$}

Novel homo- and heteroleptic lithium zincates have been prepared by co-complexation reactions of $\mathrm{Zn}\left(\mathrm{CH}_{2} \mathrm{SiMe}_{3}\right)_{2}$ and $\mathrm{PhLi}$ in low polarity hydrocarbon solvents. X-ray crystallographic studies of products obtained by reacting the organometallic reagents in benzene or toluene yields the novel solvent-free solid state arrangement $\left[\mathrm{Li}_{4} \mathrm{Zn}_{3} \mathrm{Ph}_{5}\left(\mathrm{CH}_{2} \mathrm{SiMe}_{3}\right)_{5}\right]_{\infty}(\mathbf{1})$. Combining $\mathrm{Zn}\left(\mathrm{CH}_{2} \mathrm{SiMe}_{3}\right)_{2}$ and $\mathrm{PhLi}$ in hexane in the presence of the polydentate $N$-donors PMDETA $\left(N, N, N^{\prime}, N^{\prime \prime}, N^{\prime \prime}\right.$-pentamethyldiethylenetriamine) or TMEDA $\left(N, N, N^{\prime}, N^{\prime}\right.$-tetramethylethylenediamine $)$ reveal monomeric heteroleptic [(PMDETA)LiZn $\left.\left(\mathrm{CH}_{2} \mathrm{SiMe}_{3}\right)_{2} \mathrm{Ph}\right]$ (2), and homoleptic [(TMEDA)LiZn $\left.\left(\mathrm{CH}_{2} \mathrm{SiMe}_{3}\right)_{3}\right]$ (3) the result of a disproportionation process; respectively. NMR spectroscopic studies suggest that $\mathbf{2}$ and 3 retain their discrete contacted ion-pair solid-state structures in benzene solution. Variable temperature NMR spectroscopic studies of $\mathbf{2}$ in $d_{8}$-THF reveals a complex equilibrium also including [ $\left.\mathrm{LiZn}\left(\mathrm{CH}_{2} \mathrm{SiMe}_{3}\right)_{3}\right],\left[\mathrm{LiZn}\left(\mathrm{CH}_{2} \mathrm{SiMe}_{3}\right) \mathrm{Ph}_{2}\right]$ and $\left[\mathrm{LiZnPh}{ }_{3}\right]$; an analogous equilibrium process to $\mathbf{1}$ in THF. This study further highlights the complexity of these reactions which at first would appear simple.

Keywords: zincates, lithium, solvent effects, bimetallic chemistry, co-complexation

\section{$\underline{\text { Introduction }}$}

Heterobimetallic reagents are of great value in synthetic chemistry due to their ability to exhibit substantially different reactivity to their monometallic constituents. These reagents often exist as a combination of a highly polar alkali-metal with a metal of lower polarity, such as $\mathrm{Mg}, \mathrm{Zn}$ or $\mathrm{Al}$, and regularly take the form of an 'ate' complex whereby the less polar metal accepts all the anionic ligands around it to give a complex of general formula [AM] ${ }^{+}$ $\left[M_{x} R_{x+1}\right]^{-}$(where $A M=$ alkali-metal and $M=$ less polar metal).$^{[1]}$ Alkali-metal zincates in particular have shown utility in a number of fundamental chemical transformations including zinc-halogen exchange, ${ }^{[2]}$ nucleophilic arylations ${ }^{[3]}$ and alkylations, ${ }^{[4]}$ and deprotonative metallation ${ }^{[5]}$ amongst other transformations. ${ }^{[6]}$

Heteroleptic organozinc compounds, including zincates, are known to undergo Schlenk-type equilibria and redistribution processes, which can lead to the presence of several species coexisting in solution (Figure 1). ${ }^{[7]}$ Such equilibria complicate the synthesis and isolation of pure heteroleptic species, particularly when the components have similar thermodynamic stability, for example when the ligands have similar steric bulk or are bound through the same element (i.e. they are all carbanions). ${ }^{[8]}$ 


$$
\begin{aligned}
& \mathrm{R}_{2} \mathrm{Zn}+\mathrm{R}_{2}^{\prime} \mathrm{Zn} \rightleftharpoons 2 \mathrm{RR}^{\prime} \mathrm{Zn} \\
& {\left[\mathrm{R}_{3} \mathrm{Zn}\right]^{-}+\left[\mathrm{R}_{3}{ }_{3} \mathrm{Zn}\right]^{-} \rightleftharpoons\left[\mathrm{RR}_{2}{ }_{2} \mathrm{Zn}\right]^{-}+\left[\mathrm{R}_{2} \mathrm{R}^{\prime} \mathrm{Zn}\right]^{-}}
\end{aligned}
$$

Figure 1: Schlenk-type equilibria for heteroleptic organozinc and zincate species

Co-complexation approaches are widely applied in the formation of alkali-metal zincates, ${ }^{[9]}$ and represent an appealing synthetic strategy as reactions can be conducted in weak- or non- coordinating solvents, such as hexane and benzene. In co-complexation processes, a Lewis basic donor ligand is often required to facilitate the assembly of organometallic reagents and control the aggregation level, thus giving a well-defined molecular ate complex. However, non-solvated ate complexes are also desirable as the absence of a deaggregating agent can facilitate the polymetallation of substrates. ${ }^{[10]}$ A particularly useful carbanionic ligand is trimethylsilylmethyl $\left(\mathrm{CH}_{2} \mathrm{SiMe}_{3}\right)$, combining good stability (in part due to a lack of $\beta$-hydrogen atoms) with reasonable steric bulk which helps confer solubility on non-solvated ates in less-polar solvents. A series of homoleptic trimethylsilylmethyl alkalimetal zincates were recently prepared and crystallographically characterized, with the role of common polydentate Lewis donors such as TMEDA and PMDETA upon their structures then assessed (Figure 2). ${ }^{[11]}$

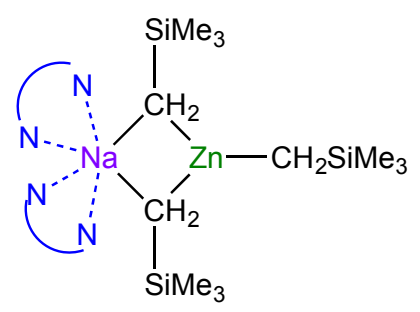

(A)<smiles>C[SiH3]C1(CC(C)(C)C)C([SiH3])[Te]1(C)C</smiles>

(C)<smiles>CC[Te](CC)C([As])(CC)[Al]1NCCCN1</smiles>

(B)

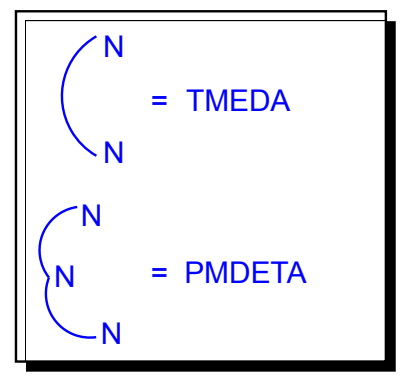

Figure 2: Chemdraw representation of a relevant selection of crystallographically characterised homoleptic zincates containing $\mathrm{CH}_{2} \mathrm{SiMe}_{3}$ ligands

Although several heteroleptic zincates have been prepared using this interlocking cocomplexation approach, most of them combine different types of anionic ligands such as amide and alkyl groups. ${ }^{[5 a, 9 b, 12]}$ Contrastingly, the number of structurally defined zincate complexes containing different C-donor ligands within the same molecular framework is notably scarce. Furthermore, in some cases these complexes are the result of a side reaction between a homoleptic zincate and the solvent, as shown by Purdy for $\left[\mathrm{KZn}\left(\mathrm{CH}_{2} \mathrm{SiMe}\right)_{2} \mathrm{Ph}\right]$, which was obtained when $\left[\mathrm{KZn}\left(\mathrm{CH}_{2} \mathrm{SiMe}_{3}\right)_{3}\right]$ was dissolved in benzene. ${ }^{[13]}$ Interestingly, from a synthetic point of view, it should be noticed that heteroleptic $\left\{\mathrm{Zn}\left(\mathrm{CH}_{2} \mathrm{SiMe}_{3}\right)_{2}(\text { aryl })\right\}^{-}$anions, prepared in situ by mixing $\mathrm{ZnCl}_{2}, \mathrm{Me}_{3} \mathrm{SiCH}_{2} \mathrm{MgCl}$, 
ArylMgCl and $\mathrm{LiCl}$, have been found to be chemoselective arylating reagents, capable of transferring their aryl group to organic substrates such as ketones and imines. ${ }^{[14]}$

Building on our previous work on the rational design of alkali-metal zincates and considering the effectiveness of the trimethylsilylmethyl group in conferring solubility and stability on sblock organometallics, we were interested in extending our synthetic studies by incorporating this ligand into heteroleptic carbanionic systems, first by looking at unsolvated species and then by investigating the role that Lewis donors play on their solid state and solution constitution. Focussing on the phenyl group as the associated ligand, we now present our findings in this area.

\section{$\underline{\text { Results and Discussion }}$}

\section{Synthesis of a solvent free heteroleptic zincate}

We commenced our studies by attempting a co-complexation reaction between equimolar amounts of PhLi and $\mathrm{Zn}\left(\mathrm{CH}_{2} \mathrm{SiMe}_{3}\right)_{2}$ in hexane in the absence of any donors. This was carried out at room temperature and, after stirring for 15 minutes, led to the formation of a white precipitate. However when the reaction was conducted in benzene a colourless solution was obtained, from which crystals were deposited upon standing overnight at room temperature (34 \% crystalline yield). The resulting structure, $\left(\mathrm{Zn}_{3} \mathrm{Li}_{4}\left(\mathrm{CH}_{2} \mathrm{SiMe}_{3}\right)_{5} \mathrm{Ph}_{5}\right)(\mathbf{1})$ was determined by X-ray crystallographic studies (Figure 3 ).
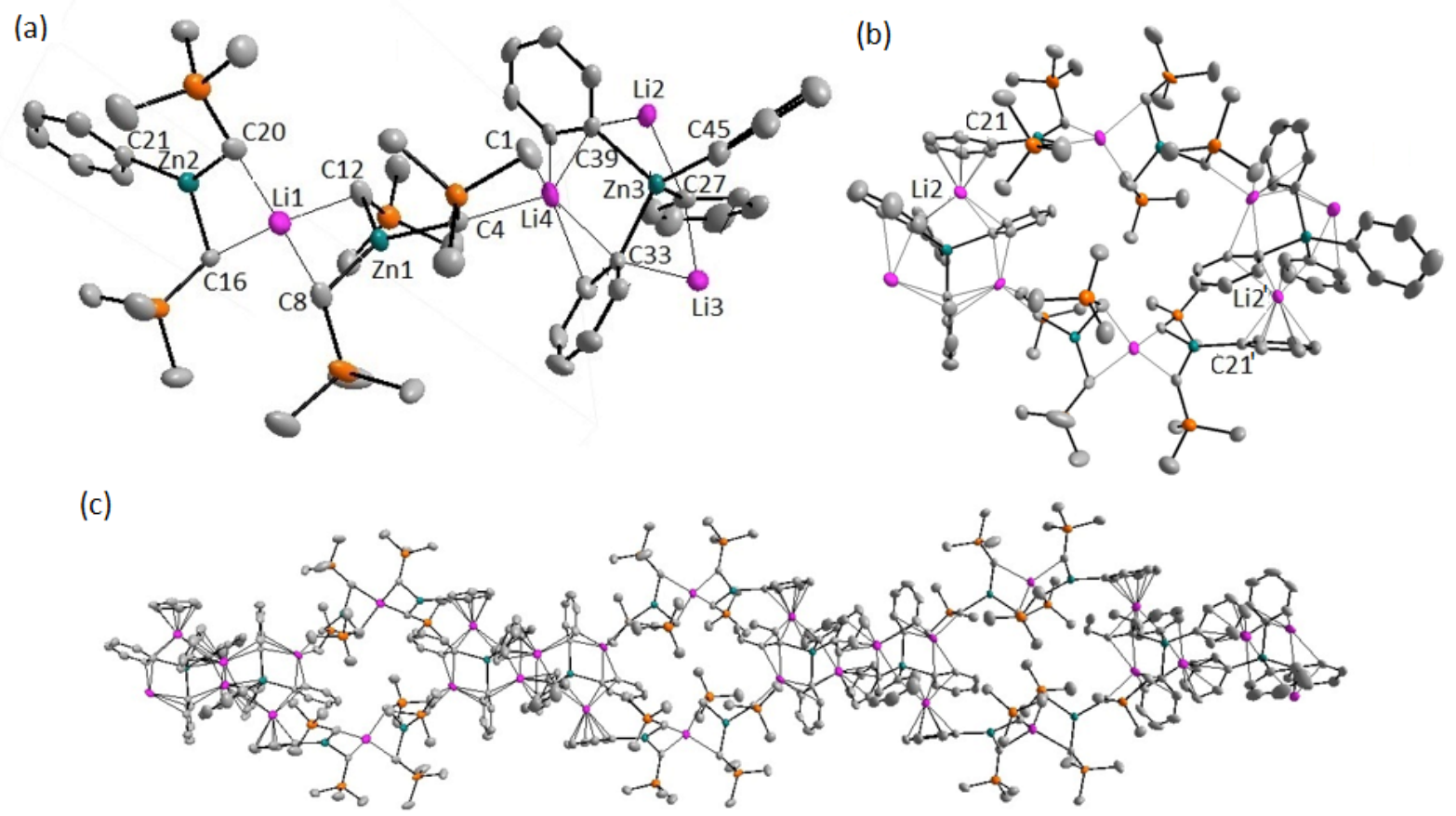

Figure 3: Solid-state structure of $\mathbf{1}$ with thermal ellipsoids drawn at $40 \%$ probability level. Hydrogen atoms are omitted for clarity; a) asymmetric unit; b) dimeric ring structure formed

by cation- $\pi$ interactions; $c$ ) coordination polymer propagated by cation- $\pi$ interactions. Symmetry operation to generate equivalent atoms labelled ': $-x,-y$, $-z$. Selected bond lengths $(\AA ̊)$ and angles ( ${ }^{\circ}$ ): Zn1-C21 2.020(7); Zn1-C16 2.083(7); Zn1-C20 2.058(7); Li1-C16 2.368(15); Li1-C20 2.244(18); Li1-C8 2.457(14); Li1-C12 2.389(17); Zn1-C4 2.037(7); Zn1-C8 2.052(7); Zn1-C12 2.084(7); Li4-C4 2.267(13); Li4-C33 2.299(15); Li4-C39 2.300(14); Zn3-C27 2.104(8); 
Zn3-C33 2.120(7); Zn3-C39 2.109(7); Zn3-C45 2.055(8); Li2-C37 2.367(15); Li2-C39 2.330(17); Li3-C27 2.368(15); Li3-C33 2.367(17); C21-Zn2-C20 132.4(3); C20-Zn2-C16 116.6(3); C16-Zn2C21 110.9(3); C20-Li1-C12 109.1(6); C16-Li1-C8 111.7(6); C20-Li1-C16 99.6(6); C12-Li1-C8 96.5(5); C12-Zn1-C4 111.5(3); C4-Zn1-C8 126.4(3); C8-Zn1-C12 121.9(3); C4-Li4-C39 113.1(6); C39-Li4-C33 95.0(5); C33-Li4-C4 119.4(6); C45-Zn3-C39 108.0(3); C45-Zn3-C27 114.0(3); C27Zn3-C39 107.6(3); C27-Zn3-C33 104.0(3).

The asymmetric unit of $\mathbf{1}$ can be described as a contacted ion-pair structure containing four $\mathrm{Li}$ and three $\mathrm{Zn}$ atoms in a variety of coordination environments, along with five phenyl and five $\mathrm{CH}_{2} \mathrm{SiMe}_{3}$ anions providing charge balance. Symmetry expansion reveals that two asymmetric units assemble in a head-to-tail fashion into a dimeric ring, held together by interactions between the $\pi$ electron density of an aromatic ring and lithium. These rings further assemble into a 1D polymeric chain, directed by further examples of such interactions.

The asymmetric unit of $\mathbf{1}$ is shown in Figure 3(a) and can be envisaged as a co-complex of three distinct parts, namely [ $\left.\mathrm{LiZn}\left(\mathrm{CH}_{2} \mathrm{SiMe}_{3}\right)_{2} \mathrm{Ph}\right]$, [ $\left.\mathrm{LiZn}\left(\mathrm{CH}_{2} \mathrm{SiMe}_{3}\right)_{3}\right]$ and $\left[\mathrm{Li}_{2} \mathrm{ZnPh}_{4}\right]$. Starting with the first segment, $\mathrm{Zn} 2$ is in a distorted trigonal geometry, $\sigma$-bonded to one phenyl group and two $\mu_{2}$-bridging $\mathrm{CH}_{2} \mathrm{SiMe}_{3}$ groups, which link to Li1. In the second segment Li1 interacts with two further $\mu_{2}$-bridging $\mathrm{CH}_{2} \mathrm{SiMe}_{3}$ groups giving Li1 a distorted tetrahedral

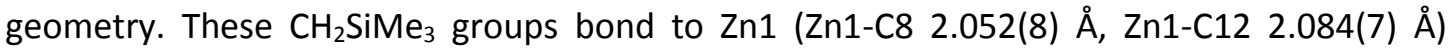
which is in a distorted trigonal planar geometry. A $\sigma$-bond to a third $\mathrm{CH}_{2} \mathrm{SiMe}_{3}$ group completes the $\mathrm{Zn}$ coordination environment (Zn1-C4 2.037(7) $\AA$ ). The third section is composed of a central tetrahedral $\mathrm{Zn}$ cation (Zn3) $\sigma$-bonded to four phenyl groups. Lying between two of the phenyl groups, forming Li-aryl $\pi$ interactions, and the last $\mathrm{CH}_{2} \mathrm{SiMe}_{3}$ group of segment 2 is $\mathrm{Li}(4)$, interacting with both the anionic $\mathrm{CH}_{2}$ part and the Me group of a $\mathrm{CH}_{2} \mathrm{SiMe}_{3}$, via a medium-long electrostatic interaction. ${ }^{[1]}$ The Li4-C1 interaction distance is 2.5744(2) $\AA$, similar to the analogous interaction in the solid state structure of [ $\left.\mathrm{LiZn}\left(\mathrm{CH}_{2} \mathrm{SiMe}_{3}\right)_{3}\right](2.515(4) \AA$ ) (Figure $2 \mathrm{C}) .{ }^{[11]}$ Finally, two further interstitial Li cations reside between the phenyl rings around $\mathrm{Zn} 3$. Li2 interacts in a $\eta^{1}$ fashion with each of the ipsocarbons C27 and C39, whilst Li3 interacts in the same manner to C27 and C33.

The extended structure of 1 reveals that the asymmetric unit assembles with a symmetry generated molecule in a head-to-tail arrangement giving a dimeric ring structure. A series of $\mathrm{Li}-\pi$ interactions facilitate this arrangement. Specifically, Li2 interacts with arene ring C21'C26' of a symmetry equivalent molecule via a $\eta^{6}$ interaction (Figure $3 \mathrm{~b}$ ). Li-C distances range from 2.400(15) - 2.481(17) $\AA$, longer than those in the benzene solvated species $\left[\mathrm{C}_{6} \mathrm{H}_{6} \cdot \mathrm{LiC}_{6} \mathrm{H}_{3}-\right.$ 2,6-Trip 2 ] (Trip $\left.=2,4,6-{ }^{i} \mathrm{Pr}_{3} \mathrm{C}_{6} \mathrm{H}_{2}\right)$, ${ }^{[15]}$ in which the average $\mathrm{Li}-\mathrm{C}$ distance is $2.23(2) \AA$, and comparable with the ate complex $\left\{\mathrm{FeBr}_{2} \mathrm{Li}\left[2,4,6-\mathrm{Me}_{3} \mathrm{PhN}\left(\mathrm{SiMe}_{2}\right)\right]_{2} \mathrm{O}\right\}_{2}$, where $\mathrm{Li}-\mathrm{C}$ distances range from $2.481(9)-2.532(11) .^{[16]}$

Interstitial Li3 is involved in a $\eta^{6} \mathrm{Li}$-arene interaction with the phenyl group C45'-C50' from an adjacent dimeric ring. Two of these non-covalent interactions are present, at each end of the ring giving rise to a novel $1 \mathrm{D}$ polymer (Figures $3 \mathrm{C}$ and 4 ). In this case the $\eta^{6}$ Li-arene distances range from $2.433(16)$ to $2.501(15) \AA$. 


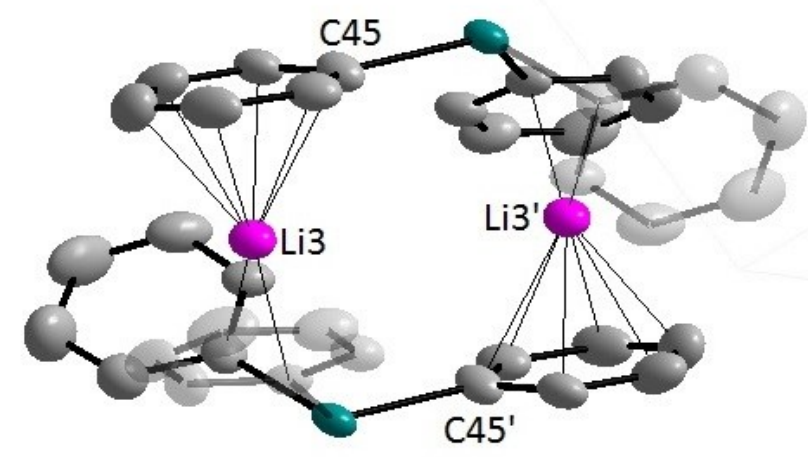

Figure 4: Li- $\pi$ interactions leading to the polymerisation of dimeric units in $\mathbf{1}$

That a polymeric species is formed when the reaction is conducted in donor-free conditions is expected, since several large aggregates have been synthesized under similar conditions. $\mathrm{PhLi}$ exists in the solid state as a polymeric zig-zag ladder, with the fundamental [LiPh $]_{2}$ units linked by interactions between the lithium atoms and the $\pi$-systems of the phenyl rings. ${ }^{[17]}$ The interactions are unequal with $\mathrm{Li}-\mathrm{C}_{\text {ipso }}$ and $\mathrm{C}_{\text {ortho }}(2.401(12) \AA$ and $2.514(14) / 2.534(14) \AA$ ) shorter than $\mathrm{Li}_{-} \mathrm{C}_{\text {para }}$ and $\mathrm{Li}-\mathrm{C}_{\text {meta }}$ (ranging $2.715(15)$ to $2.862(14) \AA$ ). The average $\mathrm{Li}-\mathrm{C}_{\text {ispo }}$ interaction in 1 is $2.328 \AA$. Power notes that $\pi$-interactions are a common feature in $\sigma$ bonded lithium aryl structures and this is the case in 1 , which contains both $\eta^{2}$ and $\eta^{6}$

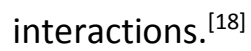

$\mathrm{ZnPh}_{2}$ exists as a dimer $\left[\mathrm{PhZn}(\mu-\mathrm{Ph})_{2} \mathrm{ZnPh}\right]$ in the solid state, ${ }^{[19]}$ which can be regarded as two monomers weakly connected by $\pi$ interactions between $\mathrm{Zn}$ and the ipso carbon of a phenyl group. These interactions are asymmetric, with $\mathrm{Zn}-\mathrm{C}$ lengths ranging from 2.006(5) to 2.442(4) $\AA$. The terminal $\mathrm{Zn}-\mathrm{C} \sigma$-bonds are 1.941(4) and 1.951(5) $\AA$, with an average distance of $1.946 \AA$. 1 contains five non-terminal $Z n-C_{\text {ipso }} \sigma$-bonds, which have a slightly longer average distance of $2.063 \AA$.

$\mathrm{LiCH}_{2} \mathrm{SiMe}_{3}$ forms a hexamer in the solid state, aggregating to satisfy the coordination requirements of the $\mathrm{Li}$ atoms. ${ }^{[20]}$ Two distinct $\mathrm{Li}-\mathrm{C}$ bond types are present in the structure, (average distances 2.20 and $2.27 \AA$ ), both distances are shorter than the average Li-C bonds found in 1, $2.384 \AA$. The lithium zincate $\left[\mathrm{LiZn}\left(\mathrm{CH}_{2} \mathrm{SiMe}_{3}\right)_{3}\right]$ exists as an infinite $1 \mathrm{D}$ chain, with $\mathrm{Li}$ not only binding to the $\mathrm{CH}_{2}$ groups in the monosilyl groups but also to a methyl group. ${ }^{[1]}$ $\mathrm{Li}-\mathrm{CH}_{2}$ distances in $\left[\mathrm{LiZn}\left(\mathrm{CH}_{2} \mathrm{SiMe}_{3}\right)_{3}\right]$ average at $2.241 \AA$, shorter than the previously mentioned corresponding distances in $\mathbf{1}$.

Few solvent free mixed aryl/alkyl heteroleptic zincate structures are known. Lennartson and Hedström prepared polymeric $\left[\mathrm{NaZnEt}_{2} \mathrm{Ph}\right]_{\infty}$ and George and Purdy prepared the polymeric potassium zincate, $\left[\mathrm{KZn}\left(\mathrm{CH}_{2} \mathrm{SiMe}_{3}\right)_{2} \mathrm{Ph}\right]_{\infty}$ via metallation of benzene (vide supra). ${ }^{[13,21]}$ Another alkali-metal zincate, potassium tri(cyclopentadienyl)zincate, exists as a twodimensional network. ${ }^{[22]}$ Structures of solvent free homoleptic alkyl zincates are also few in number but include lithium tetramethylzincate, ${ }^{[23]}$ which exists as a three-dimensional network, and $\mathrm{MZn}\left(\mathrm{CH}_{2} \mathrm{SiMe}_{3}\right)_{3}(\mathrm{M}=\mathrm{Li}, \mathrm{Na}, \mathrm{K})$, which all exhibit supramolecular assemblies; a linear polymeric chain in the case of $\mathrm{Li}$, and three-dimensional and two-dimensional coordination networks for $\mathrm{Na}$ and $\mathrm{K}$ respectively. ${ }^{[11]}$ Unsolvated mixed amido/alkyl lithium zincates are also known. ${ }^{[24]}$ 
In 1 it is apparent that the phenyl groups all originate from the starting PhLi and not from the deprotonation of benzene, since $\mathbf{1}$ is also isolated from the reaction of PhLi and $\mathrm{Zn}\left(\mathrm{CH}_{2} \mathrm{SiMe}_{3}\right)_{2}$ in toluene rather than benzene.

\section{Role of polydentate $\mathrm{N}$-donors}

In order to assess the influence that Lewis donors have on the co-complexation reactions of $\mathrm{Zn}\left(\mathrm{CH}_{2} \mathrm{SiMe}_{3}\right)_{2}$ and PhLi in hexane, we initially selected PMDETA, a commonly used neutral chelating ligand in organometallic chemistry, in the anticipation that it would coordinate to $\mathrm{Li}$ and hence favour formation of a simple bimetallic ate complex. A single equivalent of PMDETA was added to an equimolar mixture of $\mathrm{Zn}\left(\mathrm{CH}_{2} \mathrm{SiMe}_{3}\right)_{2}$ and $\mathrm{PhLi}$ in hexane. This was stirred for 15 minutes at room temperature, yielding colourless crystals upon cooling to $4^{\circ} \mathrm{C}$. $\mathrm{X}$-ray crystallographic studies identified the complex as the heteroleptic lithium zincate [(PMDETA)LiZn $\left(\mathrm{CH}_{2} \mathrm{SiMe}_{3}\right)_{2} \mathrm{Ph}$ (2) (84 \% crystalline yield, Figure 5), representing a complex which accurately reflects the stoichiometry of the starting materials.

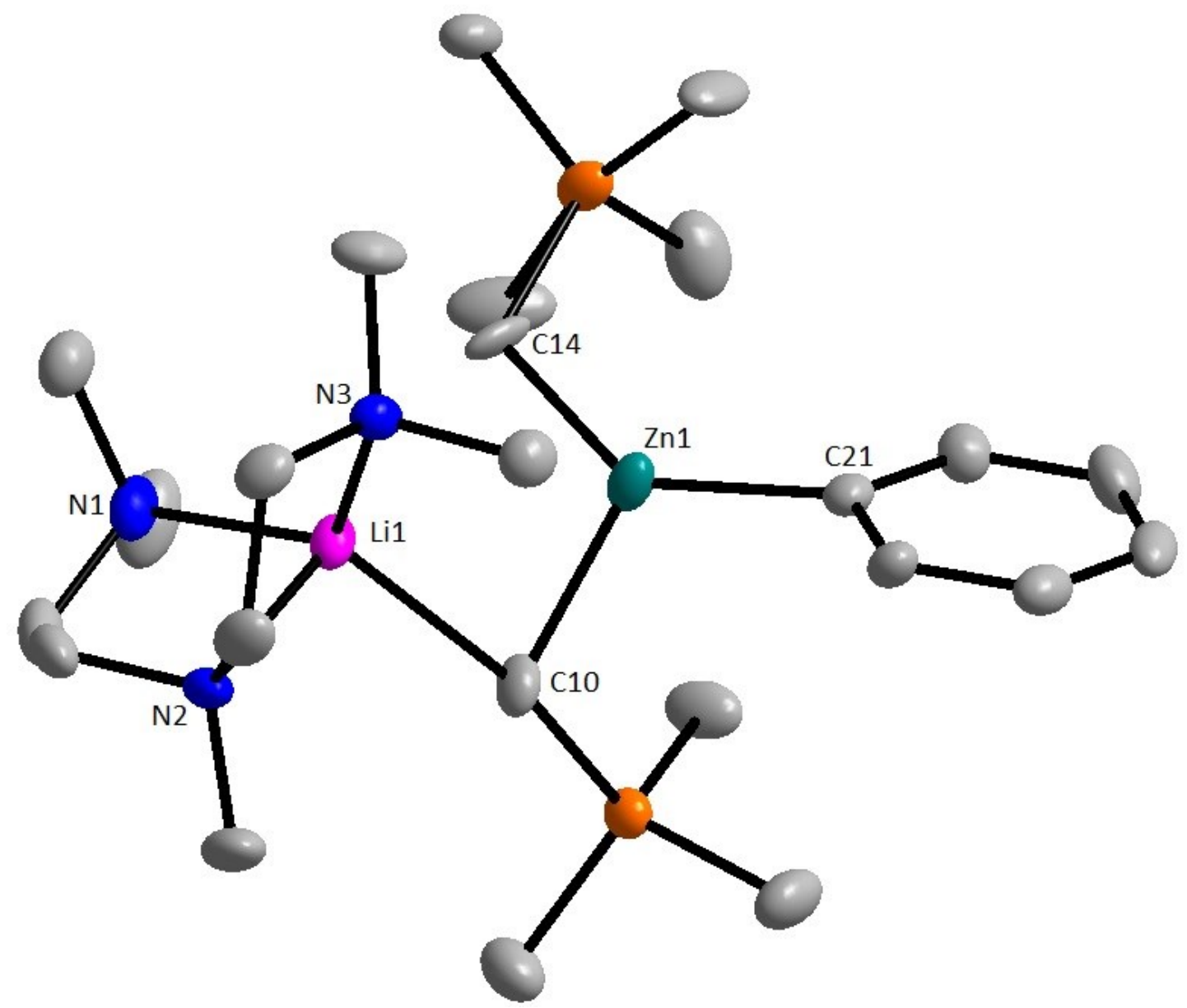

Figure 5: Solid-state structure of $\mathbf{2}$ with thermal ellipsoids drawn at $40 \%$ probability level. All hydrogen atoms and minor disordered components are omitted for clarity. Selected bond lengths ( $(\AA)$ and angles ( ${ }^{\circ}$ ): Li1-N1 2.113(6); Li1-N2 2.141(7); Li1-N3 2.102(6); Li1-C10 2.340(7); Zn1-C10 2.077(4); Zn1-C14 2.058(5); Zn1-C21 2.019(4); N1-Li1-N2 87.6(3); N2-Li1-N3 85.8(3); N1-Li1-N3 120.6(4); N1-Li1-C10, 116.4(4); N2-Li1-C10, 107.9(4); N3-Li1-C10, 121.7(3); Li1C10-Zn1 83.0(2); C10-Zn1-C21 114.1(2); C21-Zn1-C14 120.9(2); C14-Zn1-C10 124.7(2). 
Compound $\mathbf{2}$ consists of a lithium atom solvated by tridentate PMDETA, and attached to a single $\mathrm{CH}_{2} \mathrm{SiMe}_{3}$ group (Li1-C10 2.340(7) $\AA$ ), which is also bonded to a zinc atom (Zn1-C10 2.077(4) $\AA$ ). A terminally bound $\mathrm{CH}_{2} \mathrm{SiMe}_{3}$ and a phenyl group complete the complex (Zn1C14 2.058(5) $\AA$ and Zn1-C21 2.019(4) $\AA$ ). The Li1-C14 distance is 3.312(8) $\AA$, which seems too elongated to suggest any significant long-distance stabilising interaction, however, there does appear to be an influence on Li1 by $\mathrm{C} 14$ as it appears to force the lithium centre into a distorted trigonal bipyramidal geometry with the sum of the equatorial angles (where N1, $\mathrm{N} 3$ and $\mathrm{C} 10$ are in the axial positions) being $358.7^{\circ}$ and the axial angle (N2-Li1-C14) being greater than $170^{\circ}$. The groups attached to $\mathrm{Zn}$ are arranged in a distorted trigonal planar geometry, with C-Zn-C angles ranging from $114.1(2)$ to $124.7(2)^{\circ}$.

This relatively open contacted-ion pair structure, containing just one bridge between $\mathrm{Li}$ and $\mathrm{Zn}$ is reminiscent of that described for the homoleptic complex [(PMDETA) LiZn $\left(\mathrm{CH}_{2} \mathrm{SiMe}_{3}\right)_{3}$ ] (Figure 2B). In that molecule, the Li-C length is very similar, 2.338(4) $\AA$ cf. 2.340(7) $\AA$ in 2 , whereas the $\mathrm{Zn}-\mathrm{C}$ length for the terminal alkyl groups are shorter than the related bond in $\mathbf{2}$ (average $2.045 \AA$ cf. 2.058(7) $\AA$ ). The $\mathrm{Zn}-\mathrm{C}$ distance to the bridging alkyl group is 2.061(2) $\AA$, slightly shorter than that in $2(2.077(4) \AA)$. Similarly to 2 , the influence of one of the 'terminal' $\mathrm{CH}_{2} \mathrm{SiMe}_{3}$ groups of the homoleptic species also forces trigonal bipyramidal geometry on the lithium centre (sum of equatorial angles $=360^{\circ}$, axial angle $=176.9^{\circ}$ ).

We next investigated the addition of a single equivalent of the bidentate Lewis donor ligand TMEDA to a hexane mixture of $\mathrm{Zn}\left(\mathrm{CH}_{2} \mathrm{SiMe}_{3}\right)_{2}$ and $\mathrm{PhLi}$, again at room temperature. This resulted in a heterogeneous yellow mixture of solvent and oil, which upon cooling to $4^{\circ} \mathrm{C}$ afforded a crop of yellow crystals. Single crystal $\mathrm{X}$-ray diffraction studies surprisingly revealed a homoleptic alkyl zincate [(TMEDA)LiZn $\left.\left(\mathrm{CH}_{2} \mathrm{SiMe}_{3}\right)_{3}\right]$ (3) (Figure 6), in reasonable yield $\left(45 \%\right.$ based on $\left.\mathrm{Zn}\left(\mathrm{CH}_{2} \mathrm{SiMe}_{3}\right)_{2}\right)$, indicating that under these conditions the expected heteroleptic compound, [(TMEDA) LiZn $\left(\mathrm{CH}_{2} \mathrm{SiMe}_{3}\right)_{2} \mathrm{Ph}$ ], does not form.

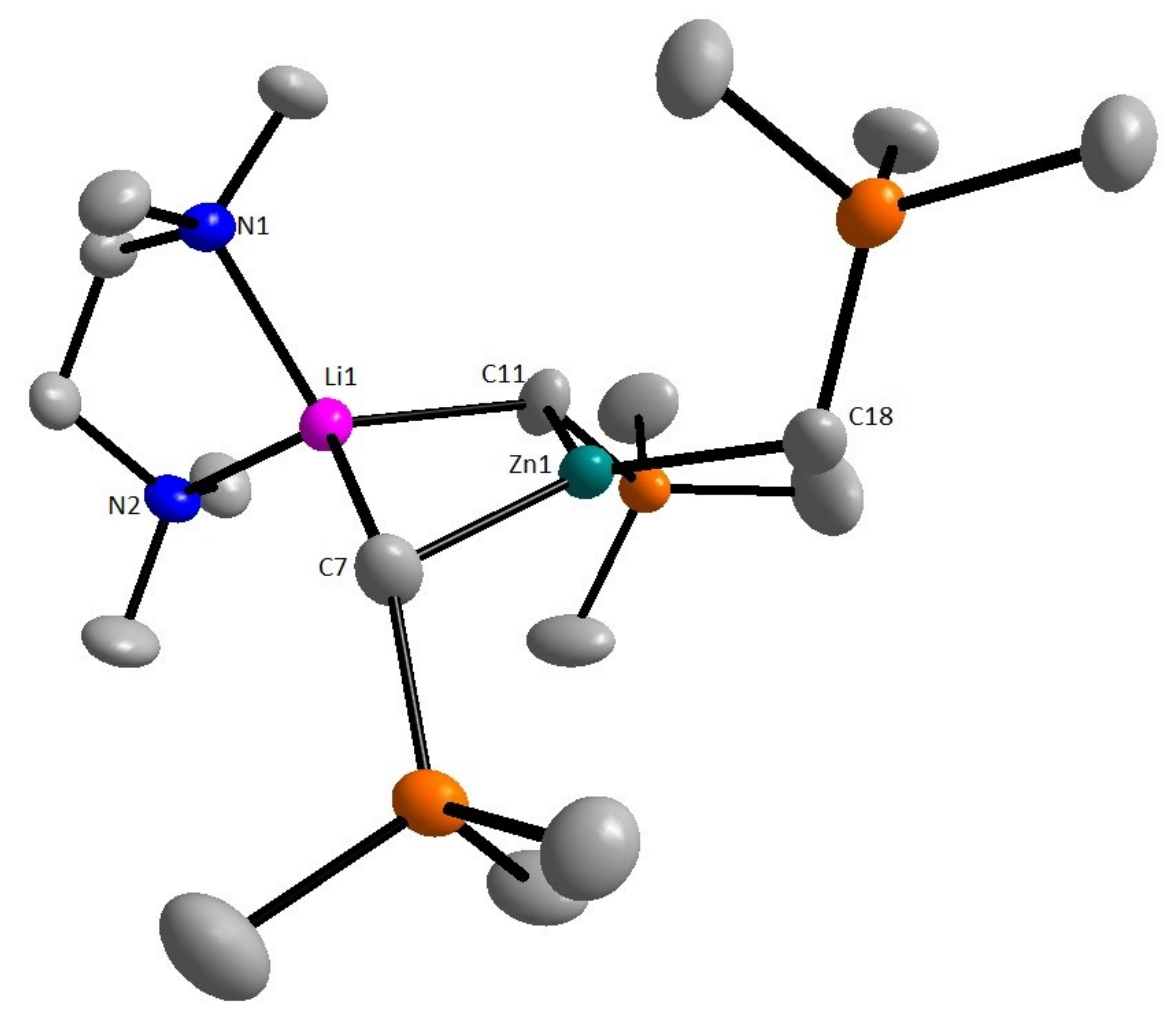


Figure 6: Solid-state structure of $\mathbf{3}$ with thermal ellipsoids drawn at $40 \%$ probability level. All hydrogen atoms and minor disordered components are omitted for clarity. Selected bond lengths ( $(\AA)$ and angles ( ${ }^{\circ}$ ): Li1-N1 2.095(4); Li1-N2 2.095(4); Li1-C7 2.325(5); Li1-C11 2.311(5);

Zn1-C7 2.071(3); Zn1-C11 2.070(3); Zn1-C18 2.005(3); N1-Li1-N2 89.43(17); C11-Li1-C7 99.83(18); Li1-C7-Zn1 69.42(13); Li1-C11-Zn1 69.69(14); C11-Zn1-C18 121.28(14); C18-Zn1C7 120.62(14); C7-Zn1-C11 117.81(12).

X-ray crystallographic studies revealed a contacted ion-pair structure for 3 containing a $\mathrm{Li}$ centre which is bonded to TMEDA and attached to two $\mu_{2}$-bridging $\mathrm{CH}_{2} \mathrm{SiMe}_{3}$ groups, with an average $\mathrm{Li}-\mathrm{CH}_{2}$ length of $2.318 \AA$. Each $\mathrm{CH}_{2} \mathrm{SiMe}_{3}$ is further bonded to the $\mathrm{Zn}$ atom (C7-Zn1, 2.071(3) $\AA$ and C11-Zn1, 2.070(3) Å) forming a non-planar four membered ring, with a value of approximately $16^{\circ}$ between planes defined by Li1-C7-Zn1 and Li1-C11-Zn1. Zn1 is also bonded to a third, terminal $\mathrm{CH}_{2} \mathrm{SiMe}_{3}$ group, and as expected has a shorter $\mathrm{Zn}-\mathrm{C}$ distance (Zn1-C18, 2.005(3) Å). The atoms around $\mathrm{Zn}$ are arranged in a distorted trigonal planar manner, presumably due to the existence of the four-membered $\mathrm{Li}-\mathrm{C}-\mathrm{Zn}-\mathrm{C}$ ring which constrains the position of the bridging ligands from an ideal geometry ( $\mathrm{C}-\mathrm{Zn}-\mathrm{C}$ range $\left.117.81(12)-121.28(14)^{\circ}\right)$. Compared with 2, the geometry at $\mathrm{Zn}$ is less distorted in homoleptic complex $\mathbf{3}$. This can be attributed to the steric bulk of the donor in $\mathbf{2}$, since PMDETA is considerably larger than TMEDA and prevents an idealized geometry around $\mathrm{Zn}$. Furthermore only one $\mathrm{CH}_{2} \mathrm{SiMe}_{3}$ bridges between $\mathrm{Zn}$ and $\mathrm{Li}$ in $\mathbf{2}$ (there are two in 3).

A related sodium zincate, [(TMEDA $)_{2} \mathrm{NaZn}\left(\mathrm{CH}_{2} \mathrm{SiMe}_{3}\right)_{3}$ ] (Figure 2A) has been described previously, produced through a co-complexation reaction between $\mathrm{NaCH}_{2} \mathrm{SiMe}_{3}$ and $\mathrm{Zn}\left(\mathrm{CH}_{2} \mathrm{SiMe}_{3}\right)_{2}$ in the presence of two equivalents of TMEDA. ${ }^{[11]}$ Evidently in $\mathbf{3}$ a single TMEDA ligand is sufficient to satisfy the smaller Li coordination sphere. In addition, the bridging $\mathrm{Zn}-\mathrm{C}$ distances in $\mathbf{3}$ (average $2.0705 \AA$ ) are slightly longer than those reported in the sodium derivate (average $2.054 \AA$ ), and the terminal $\mathrm{Zn}-\mathrm{C}$ bond is shorter in $\mathbf{3}$ (2.005(3) $\AA$ ) than in the sodium zincate complex $(2.035(3) \AA ̊)$.

As mentioned earlier, a similar complex, [(PMDETA) LiZn $\left.\left(\mathrm{CH}_{2} \mathrm{SiMe}_{3}\right)_{3}\right]$ (Figure 2B), again produced through a co-complexation reaction, containing PMDETA in place of TMEDA has also been reported..$^{12} \mathrm{~A}$ major difference between TMEDA solvated 3 and the PMDETA analogue is that the latter contains a single bridging $\mathrm{CH}_{2} \mathrm{SiMe}_{3}$ group between $\mathrm{Li}$ and $\mathrm{Zn}$ whereas in $\mathbf{3}$ the lower denticity TMEDA ligand leads to the requirement of two bridging groups to provide coordinative saturation to $\mathrm{Li}$. In the PMDETA solvated complex, the bridging $\mathrm{Li}-\mathrm{C}$ distance is $2.388(4) \AA$ and $\mathrm{Zn}-\mathrm{C}$ distance is $2.061(2) \AA$, very similar to the analogous bonds in $\mathbf{3}$.

Comparing 3 to the polymeric unsolvated homoleptic lithium zincate $\left[\mathrm{LiZn}\left(\mathrm{CH}_{2} \mathrm{SiMe}_{3}\right)_{3}\right]_{\infty}$ (Figure $2 \mathrm{C}),{ }^{[11]}$ reveals that the $\mathrm{Zn}-\mathrm{C}$ distances are similar. This polymeric structure contains metals bridged by a single $\mathrm{CH}_{2} \mathrm{SiMe}_{3}$ ligand, with a $\mathrm{Zn}-\mathrm{C}$ bond length of 2.021(2) $\AA$, and metals bridged by two such ligands, with $\mathrm{Zn}-\mathrm{C}$ distances of 2.051(2) and 2.056(2) $\AA$. The similarity in $\mathrm{Zn}-\mathrm{C}$ bond lengths in $\mathbf{3}$ and $\left[\mathrm{LiZn}\left(\mathrm{CH}_{2} \mathrm{SiMe}_{3}\right)_{3}\right]_{\infty}$ can be explained by consideration of anchoring bonding, that is, the strong $\sigma$-based $\mathrm{Zn}-\mathrm{C}$ interactions which are the foundation of the molecules and thus stabilise the structures in both molecules. ${ }^{[25]}$ The $\mathrm{Li}$ atoms in the polymer interact with the $\left\{\mathrm{Zn}\left(\mathrm{CH}_{2} \mathrm{SiMe}_{3}\right)_{3}\right\}^{-}$zincate fragment through a combination of $\mathrm{Li}$ $\mathrm{CH}_{2}$ bonds and $\mathrm{Li} \cdots \mathrm{MeSiMe}$ long distance electrostatic interactions, while such interactions are prevented in $\mathbf{3}$ by the presence of the chelating donor which provides coordinative saturation. 


\section{Relevance of structures of $\mathbf{2}$ and 3 to 1}

Interestingly the structural motifs displayed by $\mathbf{2}$ and $\mathbf{3}$ both appear in complex $\mathbf{1}$. Part (a) of Figure 7 displays a structure that resembles 2, albeit without PMDETA coordinated to Li1. Similarly part (b) resembles $\mathbf{3}$, also with Lewis donor TMEDA absent at Li1.

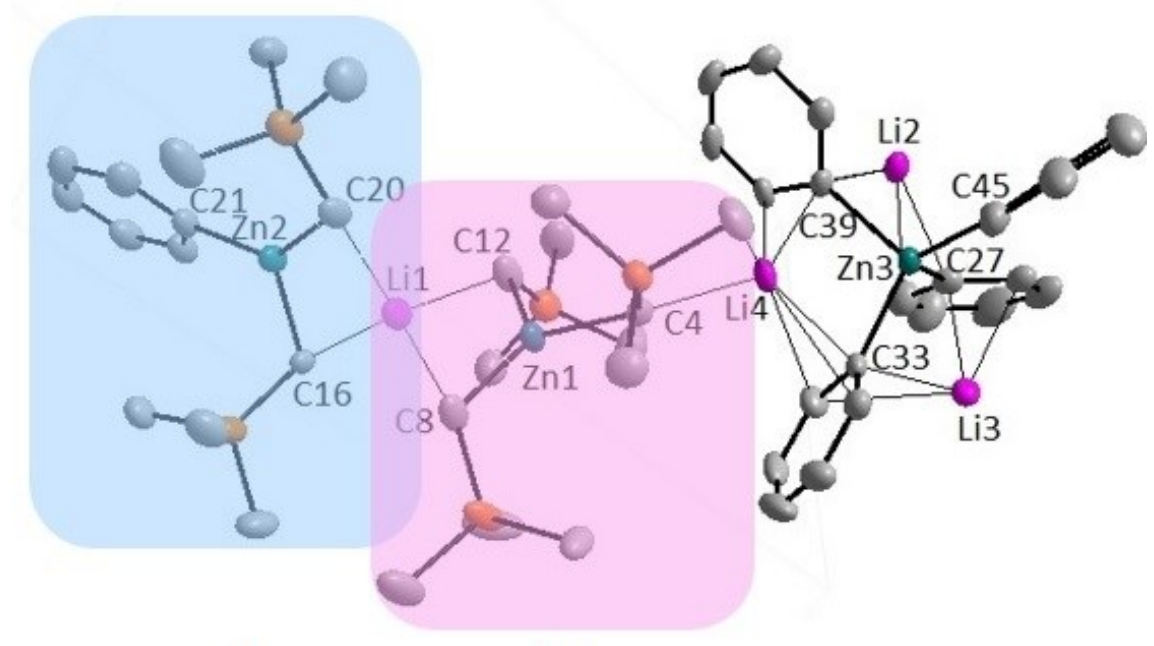

(a)

(b)

Figure 7: Asymmetric unit of $\mathbf{1}$ displaying organometallic segments of $\mathbf{2}$ and $\mathbf{3}$

Where 2 contains only a single bridging $\mathrm{CH}_{2} \mathrm{SiMe}_{3}$ group at a distance of 2.340 (7) $\AA$ from Li, 1 contains two bridging groups, with Li1-C16 2.368(15) $\AA$ and Li1-C20 2.244(18) A. The Zn-C distances are similar, with Zn1-C10 2.077(4) $\AA$ in 2, and the analogous distances in 1, Zn2$\mathrm{C} 16$ and $\mathrm{Zn2}-\mathrm{C20}$, are 2.083(7) and 2.058(7) $\AA$ respectively. The $\mathrm{Zn}-\mathrm{C}_{\mathrm{Ph}}$ distances are very similar; Zn1-C21 is 2.019(4) $\AA$ in 2 and the corresponding bond length, Zn2-C21, 2.020(7) $\AA$ in 1.

Comparing 3 and part (b) of Figure 7, both contain two bridging $\mathrm{CH}_{2} \mathrm{SiMe}_{3}$ groups between $\mathrm{Li}$ and Zn. In 3, Li1-C7 is 2.325(5) A whilst L1-C11 is 2.311(5), shorter than that in 1, with Li1-C8 2.457(14) $\AA$ and Li1-C12 2.389(17) $\AA$. The $\mathrm{Zn}-\mathrm{CH}_{2}$ bridging distances are similar with $\mathrm{Zn} 1-\mathrm{C7}$ 2.071(3) Å and Zn1-C11 2.070(3) Å in 3 whilst Zn1-C8 2.052(7) $\AA$ and Zn1-C12 2.084(7) Å in 1. $\mathrm{Zn1}-\mathrm{C} 18$, the bond to the terminal $\mathrm{CH}_{2} \mathrm{SiMe}_{3}$ group in 3 , is shorter than the related bond, $\mathrm{Zn} 1-\mathrm{C} 4$ in 1, albeit that it is not terminal in this situation, with bond lengths 2.005(4) $\AA$ and 2.037(7) Å respectively.

From the structural evidence provided by 1-3 it is clear that Lewis donor ligands play a crucial role in facilitating the ultimate identity of the isolated crystalline product. Since fragments closely related to $\mathbf{2}$ and $\mathbf{3}$ (less the Lewis donors) are present in $\mathbf{1}$, it appears that the donor ligand favours the selective crystallisation of one component of the mixture. Thus variation of Lewis donors in related systems may divulge interesting new structures and chemistry.

\section{NMR spectroscopic studies}

Polymeric 1 was insoluble in the low coordinating $C_{6} D_{6}$, suggesting that this arene solvent is unable to deaggregate its supramolecular structure. Solvated compounds $\mathbf{2}$ and $\mathbf{3}$ were 
soluble and hence were amenable to study in $\mathrm{C}_{6} \mathrm{D}_{6}$ using multinuclear ${ }^{1} \mathrm{H},{ }^{13} \mathrm{C}$ and Diffusion Ordered Spectroscopy (DOSY) NMR spectroscopy. ${ }^{[26]}$ It was however noticeable in the ${ }^{1} \mathrm{H}$ NMR spectrum of $\mathbf{2}$ that the resonances were broad, with the fine details of the aromatic resonances unresolved.

Diagnostic chemical shifts of the $\mathrm{M}-\mathrm{CH}_{2}$ groups of $\mathrm{CH}_{2} \mathrm{SiMe}_{3}$ witnessed in both the ${ }^{1} \mathrm{H}$ and ${ }^{13} \mathrm{C}$ spectra of $\mathbf{2}$ and $\mathbf{3}$ are given in Table 1, along with those of related compounds. In $\mathbf{2}$ and $\mathbf{3}$ the chemical shifts of the $\mathrm{CH}_{2}$ groups in the ${ }^{1} \mathrm{H}$ and ${ }^{13} \mathrm{C}$ spectra are very similar $\left(\mathrm{CH}_{2}=-0.75\right.$ ppm for $\mathbf{2}$ and -0.90 ppm for $\mathbf{3} ; \mathrm{CH}_{2}=0.7 \mathrm{ppm}$ for $\mathbf{2}$ and $1.9 \mathrm{ppm}$ for $\mathbf{3}$ ) and lie in the range observed in other compounds containing these ligands. ${ }^{[27]}$ Notably, both the respective ${ }^{1} \mathrm{H}$ and ${ }^{13} \mathrm{C}$ resonances are between those for the monometallic species $\mathrm{LiCH}_{2} \mathrm{SiMe}_{3}\left(\mathrm{CH}_{2}=-2.03\right.$ ppm, $\left.\mathrm{CH}_{2}=-4.4 \mathrm{ppm}\right)$ and $\mathrm{Zn}\left(\mathrm{CH}_{2} \mathrm{SiMe}_{3}\right)_{2}\left(\mathrm{CH}_{2}=-0.63 \mathrm{ppm}, \mathrm{CH}_{2}=3.2 \mathrm{ppm}\right)$, though closer to the shifts in the neutral zinc species, a trend that has previously been observed in a number of alkali-metal zincates and magnesium zincates. ${ }^{[28]}{ }^{1} \mathrm{H}$ DOSY NMR experiments suggest that the structural integrity of $\mathbf{2}$ and $\mathbf{3}$ are retained in this solvent, with resonances corresponding to the alkyl and aryl groups of $\mathbf{2}$ and the alkyl groups of $\mathbf{3}$ possessing the same diffusion coefficient as the Lewis basic ligands (Figures S10 and S14).

\begin{tabular}{ccc}
\hline Compound & $\begin{array}{c}{ }^{1} \mathrm{H} \mathrm{NMR}-\mathrm{CH}_{2} \\
\text { (ppm) }\end{array}$ & $\begin{array}{c}{ }^{13} \mathrm{C} \mathrm{NMR}^{-\mathrm{CH}_{2}} \\
(\mathrm{ppm})\end{array}$ \\
\hline $\mathrm{Li}\left(\mathrm{CH}_{2} \mathrm{SiMe}_{3}\right)$ & -2.03 & -4.4 \\
$\mathrm{Zn}\left(\mathrm{CH}_{2} \mathrm{SiMe}_{3}\right)_{2}$ & -0.63 & 3.2 \\
{$\left[\mathrm{LiZn}\left(\mathrm{CH}_{2} \mathrm{SiMe}_{3}\right)_{3}\right]$} & -1.11 & 3.2 \\
{$\left[(\mathrm{PMDETA}) \mathrm{LiZn}\left(\mathrm{CH}_{2} \mathrm{SiMe}_{3}\right)_{3}\right]$} & -0.92 & 2.4 \\
$\mathbf{2}$ & -0.75 & 0.7 \\
$\mathbf{3}$ & -0.90 & 1.9
\end{tabular}

Table 1: Selected chemical shifts in the ${ }^{1} \mathrm{H}$ and ${ }^{13} \mathrm{C}$ NMR spectra for $\mathbf{2}$ and $\mathbf{3}$ and related species in $\mathrm{C}_{6} \mathrm{D}_{6}$

In species containing phenyl groups the ipso-C is usually very sensitive to changes in chemical environment, however in the case of $\mathbf{2}$, this resonance could not be adequately resolved. The ortho-, meta- and para- chemical shifts in both ${ }^{1} \mathrm{H}$ and ${ }^{13} \mathrm{C}$ spectra are virtually identical to that of $\mathrm{ZnPh}_{2}$, however the DOSY NMR spectrum suggests that the aromatic group is still part of the same molecule as the $\mathrm{CH}_{2} \mathrm{SiMe}_{3}$ ligands.

Given the broad nature of the resonances of 2 in $\mathrm{C}_{6} \mathrm{D}_{6}$, we changed to the Lewis donor solvent $d_{8}$-THF. However, at $298 \mathrm{~K}$ the ${ }^{1} \mathrm{H}$ NMR spectrum of $\mathbf{2}$ displayed three very broad aromatic resonances $(7.70,6.91$ and $6.77 \mathrm{ppm})$, along with two broad resonances corresponding to the $\mathrm{CH}_{2}$ and $\mathrm{CH}_{3}$ hydrogen atoms of the $\mathrm{CH}_{2} \mathrm{SiMe}_{3}$ groups $(-0.11$ and -1.02 ppm respectively). These values are noticeably similar to those seen by Westerhausen and co-workers in their related solvent separated lithium zincate $\left[\mathrm{PhZn}\left(\mathrm{CH}_{2} \mathrm{SiMe}\right)_{2}\right]^{-}\left[\mathrm{Li}(\mathrm{TMTA})_{2}\right]^{+}$ (TMTA = 1,3,5-trimethylhexahydro-1,3,5-triazine), ${ }^{[29]}$ suggesting that the THF may be replacing PMDETA and producing a solvent separated complex. Given the broadness of these resonances, variable temperature NMR studies were performed in order to investigate further. Cooling the sample to $273 \mathrm{~K}$ resulted in splitting of each of the resonances from one into three distinct sets. The chemical shifts of PMDETA indicated it was not coordinated to lithium at either temperature, presumably being displaced by bulk $d_{8}$-THF. The ${ }^{7} \mathrm{Li}$ NMR spectrum shows a single resonance suggesting that only one Li environment is present on 
the NMR timescale. Comparison of the ${ }^{1} \mathrm{H}$ NMR spectra of freshly prepared homoleptic [ $\left.\mathrm{LiZn}\left(\mathrm{CH}_{2} \mathrm{SiMe}_{3}\right)_{3}\right]$ and $\left[\mathrm{LiZnPh}_{3}{ }^{[3]}\right.$ in $d_{8}$-THF at $273 \mathrm{~K}$ led to the observation that both species were present, with coincident resonances at -1.14 and $-0.14 \mathrm{ppm}$ for $\left[\mathrm{LiZn}\left(\mathrm{CH}_{2} \mathrm{SiMe}_{3}\right)_{3}\right]$ and coincident resonances at $6.88,7.00$ and $7.86 \mathrm{ppm}$, corresponding to [ $\mathrm{LiZnPh}_{3}$ ]. [ $\left.\mathrm{LiZn}\left(\mathrm{CH}_{2} \mathrm{SiMe}\right)_{2} \mathrm{Ph}\right]$ and a species we tentatively assigned as [ $\left.\mathrm{LiZn}\left(\mathrm{CH}_{2} \mathrm{SiMe}_{3}\right) \mathrm{Ph}_{2}\right]$ are also thought to be present in the solution.

Figure 8 displays overlays of [ $\left.\mathrm{LiZn}\left(\mathrm{CH}_{2} \mathrm{SiMe}_{3}\right)_{3}\right]$, [ $\left.\mathrm{LiZn}\left(\mathrm{CH}_{2} \mathrm{SiMe}_{3}\right) \mathrm{Ph}_{2}\right]$ (prepared in situ by addition of equimolar $\mathrm{Li}\left(\mathrm{CH}_{2} \mathrm{SiMe}_{3}\right)$ to $\mathrm{ZnPh}_{2}$ in $d_{8}-\mathrm{THF}$ ), [ $\mathrm{LiZnPh}_{3}$ ] and $\mathbf{2}$ (at 273 and $298 \mathrm{~K}$ ). It was found that the NMR spectrum obtained for phenyl-rich [ $\mathrm{LiZn}\left(\mathrm{CH}_{2} \mathrm{SiMe}_{3}\right) \mathrm{Ph}_{2}$ ] displays the same resonances as 2 but with a lesser amount of [ $\left.\mathrm{LiZn}\left(\mathrm{CH}_{2} \mathrm{SiMe}_{3}\right)_{3}\right]$ and more [ $\left.\left.\mathrm{LiZnPh}\right]_{3}\right]$ (ratio 1:5), reflecting the greater relative amount of phenyl ligands with respect to trimethylsilylmethyl ligands. No starting material was evident in any of the spectra.

a)

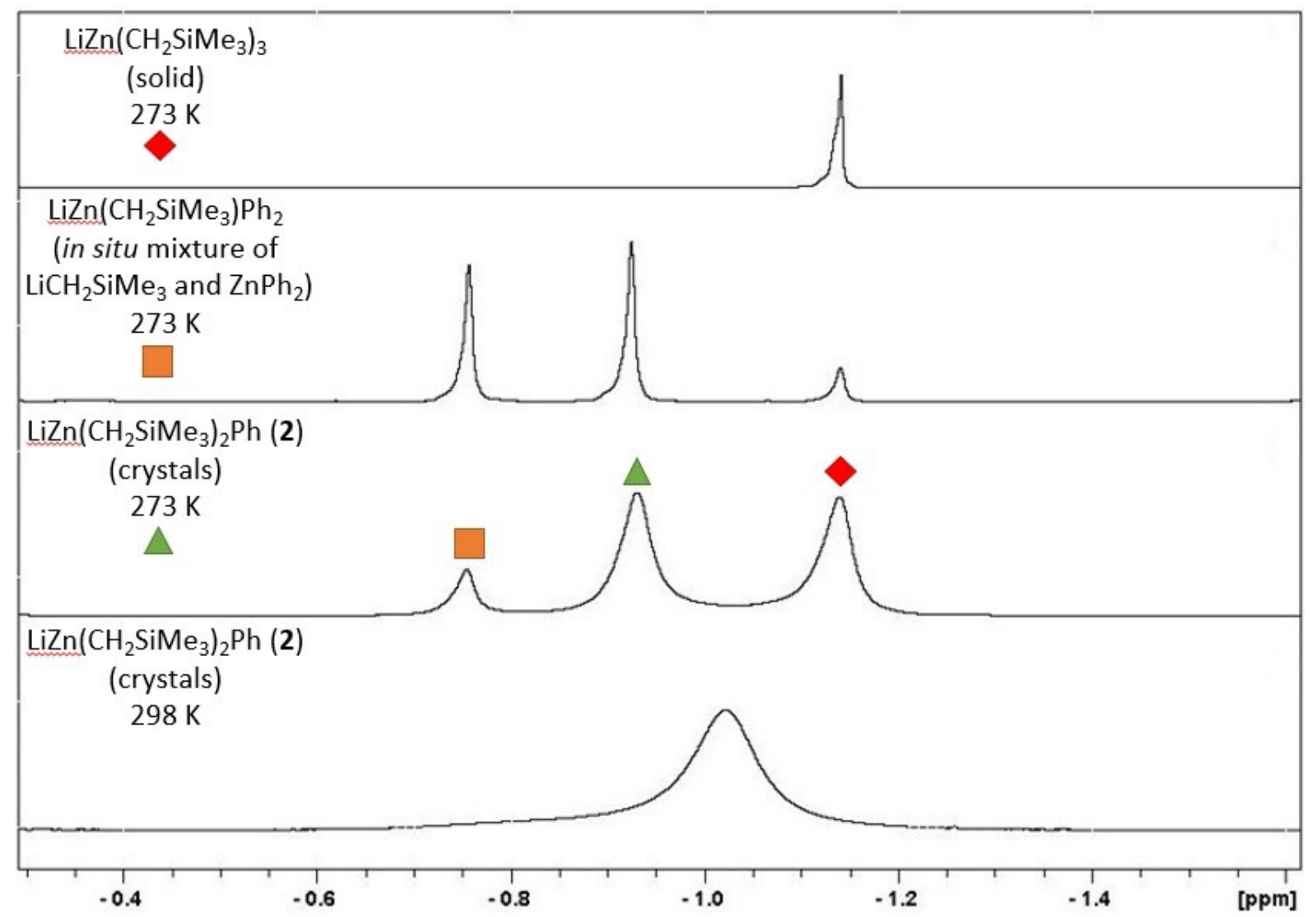

b) 


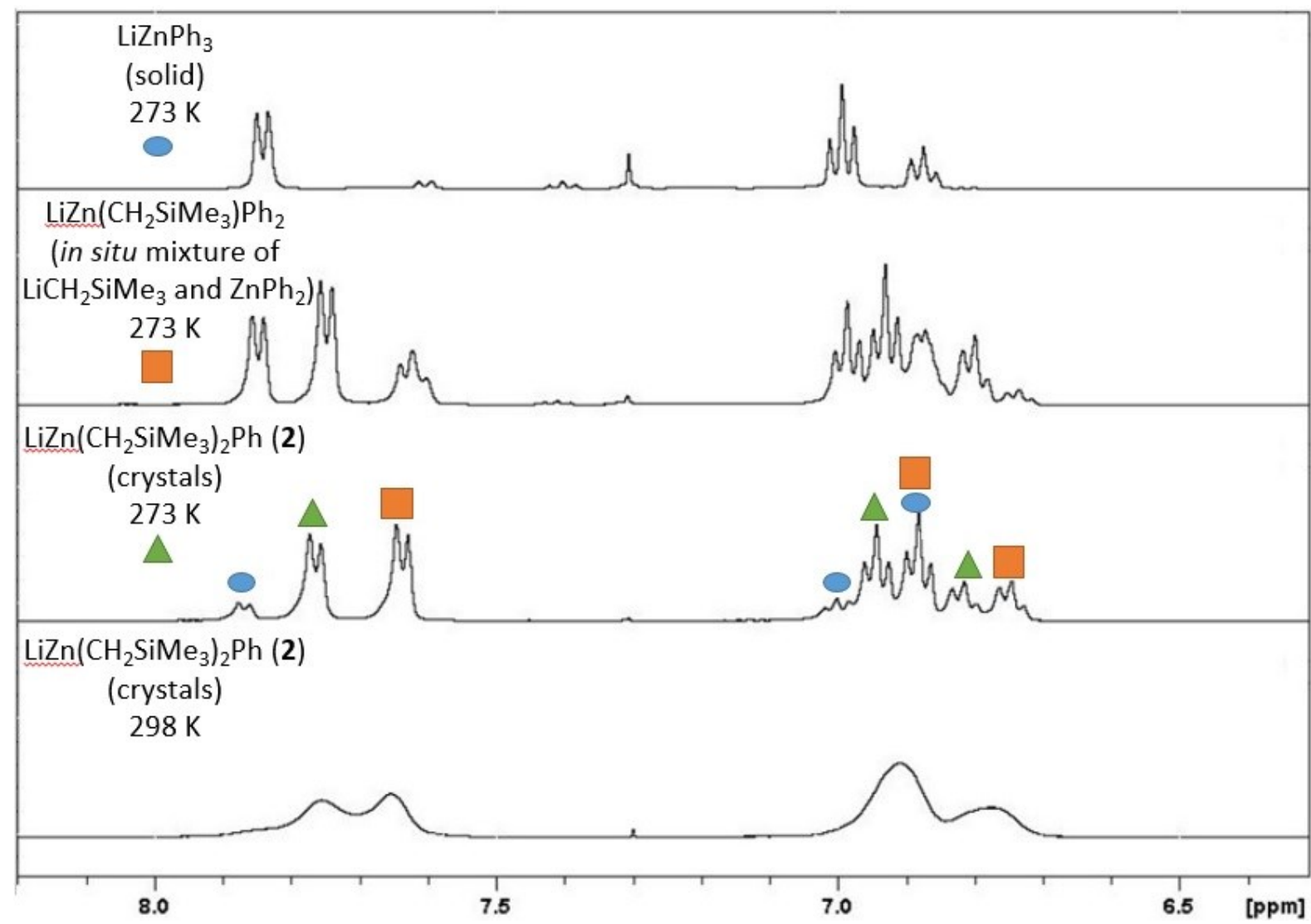

Figure 8: ${ }^{1} \mathrm{H}$ NMR spectra obtained in $d_{8}$-THF a) an overlay of the aliphatic region representing the $\mathrm{CH}_{2} \mathrm{SiMe}_{3}$ groups at $273 \mathrm{~K}$ over the spectrum of 2 obtained at $298 \mathrm{~K}, \mathrm{~b}$ ) an overlay of the aromatic region representing the phenyl groups at $273 \mathrm{~K}$ over the spectrum of 2 obtained at $298 \mathrm{~K}$.

The NMR spectroscopic studies of $\mathbf{2}$ in $d_{8}$-THF solution clearly confirm that it undergoes a complicated equilibrium process. Equilibria involving alkali metal zincates in THF solutions are known to occur and have previously been studied in-depth. ${ }^{[7 b, 30]}$ However, these previous examples involve a homometallic/heterometallic equilibrium as opposed to multiple heterobimetallic species as is the case here. The intricate nature of THF solutions of 2 illustrates the experimental complexity of working with heteroleptic zincates of these type, where several organometallic species co-exist in solution, particularly when reacting these compounds with organic substrates which can also influence the position of these equilibria.

The study also highlights that although $\mathbf{2}$ was produced in a simple co-complexation manner in a non-polar solvent, the integrity of its solid-state structure is not maintained in solution when using more polar Lewis donor solvents, which readily displace the PMDETA ligand and induce this complex equilibria.

Heteroleptic, polymeric 1 was also studied by ${ }^{1} \mathrm{H}$ and ${ }^{13} \mathrm{C}$ NMR spectroscopy in $d_{8}$-THF due to its insolubility in $\mathrm{C}_{6} \mathrm{D}_{6}$. The ${ }^{1} \mathrm{H}$ NMR spectrum at $300 \mathrm{~K}$ displayed sharp singlets at -0.90 and 0.08 ppm corresponding to $\mathrm{CH}_{2} \mathrm{SiMe}_{3}$ groups and a single set of aromatic resonances at 6.80 , 6.93 and $7.75 \mathrm{ppm}$ corresponding to the phenyl components in the molecule. Upon cooling to $273 \mathrm{~K}$, the resonance at $-0.90 \mathrm{ppm}$ broadened, as did the resonance at $7.75 \mathrm{ppm}$. Further cooling to $223 \mathrm{~K}$ and then $203 \mathrm{~K}$ led to the separation of the $\mathrm{CH}_{2}$ signals and also separation of the phenyl resonances. Comparison of the spectrum obtained at $203 \mathrm{~K}$ with the spectrum of 2 in $d_{8}$-THF at $273 \mathrm{~K}$ indicated that an analogous equilibrium process is in operation, with 
$\left[\mathrm{Zn}\left(\mathrm{CH}_{2} \mathrm{SiMe}_{3}\right)_{3}\right]^{-},\left[\mathrm{Zn}\left(\mathrm{CH}_{2} \mathrm{SiMe}\right)_{2} \mathrm{Ph}\right]^{-},\left[\mathrm{Zn}\left(\mathrm{CH}_{2} \mathrm{SiMe}_{3}\right) \mathrm{Ph}_{2}\right]^{-}$and $\left[\mathrm{ZnPh}_{3}\right]^{-}$all present in the solution (Fig S17). Although the resonances obtained at $203 \mathrm{~K}$ are broad, it is clear that the constituents of the equilibrium process are in different amounts from those in the equilibrium found in $\mathbf{2}$. This is in line with the number of $\mathrm{CH}_{2} \mathrm{SiMe}_{3}$ groups to phenyl groups in the solid state structure, with $\mathbf{1}$ containing a one to one ratio and $\mathbf{2}$ a two to one ratio.

\section{Conclusions}

Showcasing the solution complexity of heteroleptic lithium zincates, this study on the cocomplexation of $\mathrm{Zn}\left(\mathrm{CH}_{2} \mathrm{SiMe}_{3}\right)_{2}$ and $\mathrm{PhLi}$ has led to the isolation and structural elucidation of three novel heterobimetallic complexes. In the absence of any donor, both single-metal reagents self-assembled to form unique polymeric arrangement 1 , made up of a combination of $\mathrm{Zn}-\mathrm{C}$ and $\mathrm{Li}-\mathrm{C}$ bonds and medium-long distance electrostatic interactions between the $\mathrm{Li}$ atoms with the $\mathrm{Ph}$ and $\mathrm{SiMe}_{3}$ groups. Introducing $\mathrm{N}$-donor ligands PMDETA and TMEDA has allowed the isolation of monomeric species $\mathbf{2}$ and $\mathbf{3}$, with the latter being the result of a redistribution process. Advanced NMR studies have disclosed the intricate constitution of heteroleptic $\mathbf{1}$ and $\mathbf{2}$, particularly when the coordinating solvent THF is employed, where the heteroleptic zincates co-exist in equilibrium with other homo- and heterobimetallic species.

\section{Experimental}

General Conditions All reactions were performed under a protective argon atmosphere using standard Schlenk techniques. Hexane and benzene were dried by heating to reflux over sodium and benzophenone and distilled under nitrogen prior to use. TMEDA and PMDETA were distilled over $\mathrm{CaH}_{2}$ prior to use. All NMR spectra were recorded on a Bruker DPX $400 \mathrm{MHz}$ spectrometer, operating at $400.13 \mathrm{MHz}$ for ${ }^{1} \mathrm{H}, 155.50 \mathrm{MHz}$ for ${ }^{7} \mathrm{Li}$ and 100.62 $\mathrm{MHz}$ for ${ }^{13} \mathrm{C}$. All ${ }^{13} \mathrm{C}$ NMR spectra were proton decoupled.

Elemental analyses were performed using a Perkin Elmer 2400 elemental analyser.

$\mathrm{Zn}\left(\mathrm{CH}_{2} \mathrm{SiMe}_{3}\right)_{2}$ was prepared according to a literature procedure. ${ }^{[31]}$

X-ray Crystallography Crystallographic data were collected at $123(2) \mathrm{K}$ on an Oxford Diffraction diffractometer with Mo K $\alpha(\lambda=0.71073 \AA)$ or $\mathrm{Cu} K \alpha(\lambda=1.54180 \AA)$. Structures were solved using SHELXS-97 ${ }^{[32]}$ or OLEX2, ${ }^{[33]}$ while refinement was carried out on $F^{2}$ against all independent reflections by the full matrix least-squares method using the SHELXL-97 program or by the GaussNewton algorithm using OLEX2. All non-hydrogen atoms were refined using anisotropic thermal parameters. Data for compound 1 was measured from a non-single sample, with the initial data collection using an incorrect and higher symmetry unit cell. At the end of data collection the correct triclinic cell was identified and the data processed within CrysalisPro to remove the contribution of the second diffracting entity. This gave an acceptable quality structure but one with a lower percentage completeness than normal ( $88 \%)$. Recollection using other samples did not give suitable quality structures. Selected crystallographic and refinement details are given in Table S2. 
CCDC 1499390 - 1499392 contain the supplementary crystallographic data for this paper. These data can be obtained free of charge from The Cambridge Crystallographic Data Centre (http://www.ccdc.cam.ac.uk/conts/retrieving.html)

Synthesis of PhLi: To iodobenzene $(1.78 \mathrm{~mL}, 16 \mathrm{mmol})$ in $30 \mathrm{~mL}$ hexane, ${ }^{\mathrm{n}}$ BuLi was added at room temperature dropwise yielding a yellow precipitate. The mixture was stirred at room temperature for 1 hour and filtered, rinsed with hexane, dried under vacuum and stored in a glovebox. Average yield $89 \%$.

Synthesis of $\left[\mathrm{Li}_{4} \mathrm{Zn}_{3} \mathrm{Ph}_{5}\left(\mathrm{CH}_{2} \mathrm{SiMe}_{3}\right)_{5}\right]_{\infty}$ (1): A Schlenk tube was charged with $\mathrm{Zn}\left(\mathrm{CH}_{2} \mathrm{SiMe}_{3}\right)_{2}$ (120 mg, $0.5 \mathrm{mmol}$ ) and PhLi (42 mg, $0.5 \mathrm{mmol}$ ) to which $5 \mathrm{~mL}$ benzene was added. This mixture was stirred at room temperature for 15 minutes, resulting in a colourless solution. Leaving this solution standing at room temperature resulted in the formation of colourless crystals $(60 \mathrm{mg}, 34 \%) .{ }^{1} \mathrm{H}$ NMR $\left(400.13 \mathrm{MHz}, 300 \mathrm{~K}, d_{8}\right.$-THF) $\delta(\mathrm{ppm})=-0.90(\mathrm{~s}, 2 \mathrm{H}$, $\left.\left.\mathrm{CH}_{2} \mathrm{Si}\left(\mathrm{CH}_{3}\right)_{3}\right)_{2},-0.08\left(\mathrm{~S}, 9 \mathrm{H}, \mathrm{CH}_{2} \mathrm{Si}(\mathrm{CH})_{3}\right), 6.80\left(\mathrm{t}, 1 \mathrm{H}, p-\mathrm{CH},{ }^{3}\right)_{\mathrm{HH}}=7.64 \mathrm{~Hz}\right), 6.94(\mathrm{t}, 2 \mathrm{H}, m-\mathrm{CH}$, $\left.{ }^{3} J_{\mathrm{HH}}=7.20 \mathrm{~Hz}\right), 7.75\left(\mathrm{~d}, 2 \mathrm{H}, o-\mathrm{CH},{ }^{3} \mathrm{~J}_{\mathrm{HH}}=6.20 \mathrm{~Hz}\right) .{ }^{13} \mathrm{C}\left\{{ }^{1} \mathrm{H}\right\} \mathrm{NMR}\left(100.62 \mathrm{MHz}, 300 \mathrm{~K}, d_{8}-\mathrm{THF}\right) \delta$ $(\mathrm{ppm})=-2.0\left(\left(\mathrm{CH}_{2} \mathrm{Si}(\mathrm{CH})_{3}\right), 3.9\left(\mathrm{CH}_{2} \mathrm{Si}(\mathrm{CH})_{3}\right), 123.6(p-\mathrm{CH}), 125.7(m-\mathrm{CH}), 140.7(o-C H){ }^{7} \mathrm{Li}\right.$ NMR (298 K, $d_{8}$-THF) $\delta(p p m):-0.54$. Due to the air sensitive nature of this compound no satisfactory elemental analyses could be obtained.

Synthesis of [(PMDETA)LiZn $\left.\left(\mathrm{CH}_{2} \mathrm{SiMe}_{3}\right)_{2} \mathrm{Ph}\right]$ (2): A Schlenk tube was charged with $\mathrm{Zn}\left(\mathrm{CH}_{2} \mathrm{SiMe}_{3}\right)_{2}(120 \mathrm{mg}, 0.5 \mathrm{mmol})$ and $\mathrm{PhLi}(42 \mathrm{mg}, 0.5 \mathrm{mmol})$ to which $5 \mathrm{~mL}$ hexane was added. To the resulting white suspension, PMDETA $(0.11 \mathrm{~mL}, 0.5 \mathrm{mmol})$ was added. The resulting yellow solution was stirred for 15 minutes, resulting in a yellow oil from which crystal growth was possible upon cooling to $-35^{\circ} \mathrm{C}$. (209 mg, $\left.84 \%\right)$. ${ }^{1} \mathrm{H}$ NMR $(400.13 \mathrm{MHz}$, $\left.300 \mathrm{~K}, \mathrm{C}_{6} \mathrm{D}_{6}\right) \delta(\mathrm{ppm})=-0.75\left(\right.$ broad s, $\left.4 \mathrm{H}, \mathrm{CH}_{2} \mathrm{Si}\left(\mathrm{CH}_{3}\right)_{3}\right),-0.45\left(\mathrm{~s}, 18 \mathrm{H}, \mathrm{CH}_{2} \mathrm{Si}\left(\mathrm{CH}_{3}\right)_{3}\right), 1.50(\mathrm{~s}$, $\left.3 \mathrm{H}, \mathrm{NCH})_{3}\right), 1.53-1.65\left(\mathrm{~m}, 8 \mathrm{H},-\mathrm{CH}_{2} \mathrm{CH}_{2}-\right), 1.83\left(\mathrm{~s}, 12 \mathrm{H}, \mathrm{N}\left(\mathrm{CH}_{3}\right)_{2}\right), 7.24$ (broad s, $\left.1 \mathrm{H}, p-\mathrm{CH}\right), 7.28$ (broad s, $2 \mathrm{H}, m-\mathrm{CH}$ ), 8.15 (very broad s, $2 \mathrm{H}, o-\mathrm{CH}) .{ }^{13} \mathrm{C}\left\{{ }^{1} \mathrm{H}\right\} \mathrm{NMR}\left(100.62 \mathrm{MHz}, 300 \mathrm{~K}, \mathrm{C}_{6} \mathrm{D}_{6}\right) \delta$ $(\mathrm{ppm})=0.7\left(\mathrm{CH}_{2} \mathrm{Si}\left(\mathrm{CH}_{3}\right)_{3}\right), 4.5\left(\mathrm{CH}_{2} \mathrm{Si}\left(\mathrm{CH}_{3}\right)_{3}\right), 44.5\left(\mathrm{NCH}_{3}\right), 45.9\left(\mathrm{~N}\left(\mathrm{CH}_{3}\right)_{2}\right), 53.1\left(-\mathrm{CH}_{2} \mathrm{CH}_{2}-\right), 57.0$ $\left(-\mathrm{CH}_{2} \mathrm{CH}_{2}-\right), 125.7(p-\mathrm{CH}), 127.0(\mathrm{~m}-\mathrm{CH}), 140.8(o-\mathrm{CH})$. Cannot observe i-CH. ${ }^{7} \mathrm{Li}$ NMR (298 K, $\left.\mathrm{C}_{6} \mathrm{D}_{6}\right) \delta(\mathrm{ppm}):-0.42$. Elemental analysis (\%) for $\mathrm{C}_{23} \mathrm{H}_{50} \mathrm{LiN}_{3} \mathrm{Si} 2 \mathrm{Zn}$ : calcd: $\mathrm{C} 55.68, \mathrm{H} \mathrm{9.95,} \mathrm{N}$ 8.47; found C 55.31, H 9.78, N 8.84.

Synthesis of [(TMEDA)LiZn $\left(\mathrm{CH}_{2} \mathrm{SiMe}_{3}\right)_{3}$ ] (3): A Schlenk tube was charged with $\mathrm{Zn}\left(\mathrm{CH}_{2} \mathrm{SiMe}_{3}\right)_{2}$ (120 mg, $0.5 \mathrm{mmol}$ ) and PhLi (42 mg, $0.5 \mathrm{mmol}$ ) to which $5 \mathrm{~mL}$ hexane was added. To the resulting white suspension, TMEDA $(0.08 \mathrm{~mL}, 0.5 \mathrm{mmol})$ was added. The resulting yellow solution was stirred for 15 minutes, resulting in a yellow oil from which crystal growth was possible upon cooling to $-35{ }^{\circ} \mathrm{C}$. $(122 \mathrm{mg}, 45 \%) .{ }^{1} \mathrm{H}$ NMR $\left(400.13 \mathrm{MHz}, 300 \mathrm{~K}, \mathrm{C}_{6} \mathrm{D}_{6}\right) \delta(\mathrm{ppm})=$ - 0.90 (s, 6H, CH$\left.{ }_{2} \mathrm{Si}(\mathrm{CH})_{3}\right), 0.40$ (s, 27H, $\left.\mathrm{CH}_{2} \mathrm{Si}(\mathrm{CH})_{3}\right), 1.47$ (bs, $\left.4 \mathrm{H},-\mathrm{CH}_{2} \mathrm{CH}_{2}-\right), 1.71$ (bs, $12 \mathrm{H}$, $\left.\mathrm{NCH}_{3}\right) .{ }^{13} \mathrm{C}\left\{{ }^{1} \mathrm{H}\right\} \mathrm{NMR}\left(100.62 \mathrm{MHz}, 300 \mathrm{~K}, \mathrm{C}_{6} \mathrm{D}_{6}\right) \delta(\mathrm{ppm})=1.9\left(\mathrm{CH}_{2} \mathrm{Si}(\mathrm{CH})_{3}\right), 4.2\left(\mathrm{CH}_{2} \mathrm{Si}(\mathrm{CH})_{3}\right)$, $45.6\left(\mathrm{NCH}_{3}\right), 56.4\left(-\mathrm{CH}_{2} \mathrm{CH}_{2}-\right)$. ${ }^{7} \mathrm{Li} \mathrm{NMR}\left(298 \mathrm{~K}, \mathrm{C}_{6} \mathrm{D}_{6}\right) \delta(\mathrm{ppm}): 1.00$. Trace amounts of [(TMEDA)LiZn $\left(\mathrm{CH}_{2} \mathrm{SiMe}_{3}\right)_{2} \mathrm{Ph}$ ] were obtained during the formation of $\mathbf{3}$, leading to poor elemental analysis results.

\section{$\underline{\text { Acknowledgements }}$}

We would like to thank the European Research Council (ERC-Stg grant to EH) and the Royal Society of Edinburgh (BP Trust Fellowship to SDR). 


\section{$\underline{\text { References }}$}

[1] a) R. E. Mulvey, Organometallics 2006, 25, 1060; b) R. E. Mulvey, F. Mongin, M. Uchiyama, Y. Kondo, Angew. Chem. Int. Ed. 2007, 46, 3802; c) R. E. Mulvey, Acc. Chem. Res. 2009, 42, 743; d) R. E. Mulvey, Dalton Trans. 2013, 42, 6676; e) A. Harrison-Marchand, F. Mongin, Chem. Rev. 2013, 113, 7470; f) F. Mongin, A. Harrison-Marchand, Chem. Rev. 2013, 113, 7563.

[2] a) M. Uchiyama, M. Kameda, O. Mishima, N. Yokoyama, M. Koike, Y. Kondo, T. Sakamoto, J. Am. Chem. Soc. 1998, 120, 4934; b) P. Knochel, Angew. Chem. Int. Ed. 2004, 43, 1017; c) T. Furuyama, M. Yonehara, S. Arimoto, M. Kobayashi, Y. Matsumoto, M. Uchiyama, Chem. Eur. J. 2008, 14, 10348.

[3] A. Hernan-Gomez, E. Herd, M. Uzelac, T. Cadenbach, A. R. Kennedy, I. Borilovic, G. Aromi, E. Hevia, Organometallics 2015, 34, 2614.

[4] S. E. Baillie, V. L. Blair, D. C. Blakemore, D. Hay, A. R. Kennedy, D. C. Pryde, E. Hevia, Chem. Commun. 2012, 48, 1985.

[5] a) Y. Kondo, M. Shilai, M. Uchiyama, T. Sakamoto, J. Am. Chem. Soc. 1999, 121, 3539; b) M. Uchiyama, T. Miyoshi, Y. Kajihara, T. Sakamoto, Y. Otani, T. Ohwada, Y. Kondo, J. Am. Chem. Soc. 2002, 124, 8514; c) W. Clegg, B. Conway, E. Hevia, M. D. McCall, L. Russo, R. E. Mulvey, J. Am. Chem. Soc. 2009, 131, 2375; d) D. R. Armstrong, J. A. Garden, A. R. Kennedy, S. M. Leenhouts, R. E. Mulvey, P. O'Keefe, C. T. O'Hara, A. Stevenson, Chem. Eur. J. 2013, 19, 13492.

[6] M. Uchiyama, C. Wang, Top. Organomet. Chem. 2014, 47, 159.

[7] a) H. Nehl, W. R. Scheidt, J. Organomet. Chem. 1985, 289, 1; b) T. A. Mobley, S. Berger, Angew. Chem. Int. Ed. 1999, 38, 3070; c) A. J. Roberts, W. Clegg, A. R. Kennedy, M. R. Probert, S. D. Robertson, E. Hevia, Dalton Trans. 2015, 44, 8169.

[8] J. T. B. H. Jastrzebski, J. Boersma, G. van Koten, in The Chemistry of Organozinc Compounds Part 1 (Eds.: Z. Rappoport, I. Marek), Wiley, Chichester, 2006, pp. 31-137.

[9] a) E. Hevia, D. J. Gallagher, A. R. Kennedy, R. E. Mulvey, C. T. O'Hara, C. Talmard, Chem. Commun. 2004, 2422; b) P. C. Andrikopoulos, D. R. Armstrong, H. R. L. Barley, W. Clegg, S. H. Dale, E. Hevia, G. W. Honeyman, A. R. Kennedy, R. E. Mulvey, J. Am. Chem. Soc. 2005, 127, 6184; c) D. R. Armstrong, J. Garcia-Alvarez, D. V. Graham, G. W. Honeyman, E. Hevia, A. R. Kennedy, R. E. Mulvey, Chem. Eur. J. 2009, 15, 3800; d) A. R. Kennedy, J. Klett, R. E. Mulvey, D. S. Wright, Science 2009, 326, 706.

[10] a) D. R. Armstrong, A. R. Kennedy, R. E. Mulvey, R. B. Rowlings, Angew. Chem. Int. Ed. 1999, 38, 131; b) W. Clegg, K. W. Henderson, A. R. Kennedy, R. E. Mulvey, C. T. O'Hara, R. B. Rowlings, D. M. Tooke, Angew. Chem. Int. Ed. 2001, 40, 3902; c) A. J. Martinez-Martinez, D. R. Armstrong, B. Conway, B. J. Fleming, J. Klett, A. R. Kennedy, R. E. Mulvey, S. D. Robertson, C. T. O'Hara, Chem. Sci. 2014, 5, 771; d) A. J. Martinez-Martinez, A. R. Kennedy, R. E. Mulvey, C. T. O'Hara, Science 2014, 346, 834; e) W. Clegg, E. Crosbie, S. H. Dale-Black, E. Hevia, G. W. Honeyman, A. R. Kennedy, R. E. Mulvey, D. L. Ramsay, S. D. Robertson, Organometallics 2015, 34, 2580.

[11] D. R. Armstrong, H. S. Emerson, A. Hernan-Gomez, A. R. Kennedy, E. Hevia, Dalton Trans. 2014, 43, 14229. 
[12] a) W. Clegg, S. H. Dale, A. M. Drummond, E. Hevia, G. W. Honeyman, R. E. Mulvey, J. Am. Chem. Soc. 2006, 128, 7434; b) M. Uchiyama, Y. Matsumoto, D. Nobuto, T. Furuyama, K. Yamaguchi, K. Morokuma, J. Am. Chem. Soc. 2006, 128,8748 .

[13] A. P. Purdy, C. F. George, Organometallics 1992, 11, 1955.

[14] M. Hatano, O. Ito, S. Suzuki, K. Ishihara, J. Org. Chem. 2010, 75, 5008.

[15] B. Schiemenz, P. P. Power, Angew. Chem. Int. Ed. Engl. 1996, 35, 2150.

[16] G. Mund, D. Vidovic, R. J. Batchelor, J. F. Britten, R. D. Sharma, C. H. W. Jones, D. B. Leznoff, Chem. Eur. J. 2003, 9, 4757.

[17] R. E. Dinnebier, U. Behrens, F. Olbrich, J. Am. Chem. Soc. 1998, 120, 1430.

[18] R. J. Wehmschulte, P. P. Power, J. Am. Chem. Soc. 1997, 119, 2847.

[19] P. R. Markies, G. Schat, O. S. Akkerman, F. Bickelhaupt, W. J. J. Smeet, A. L. Spek, Organometallics 1990, 9, 2243.

[20] B. Tecle, A. F. M. M. Rahman, J. P. Oliver, J. Organomet. Chem. 1986, 317, 267.

[21] A. Hedström, A. Lennartson, J. Organomet. Chem. 2011, 696, 2269.

[22] E. Alvarez, A. Grirrane, I. Resa, D. Del Rio, A. Rodriguez, E. Carmona, Angew. Chem. Int. Ed. 2007, 46, 1296.

[23] E. Weiss, R. Wolfrum, Chem. Ber. 1968, 101, 35.

[24] a) G. C. Forbes, A. R. Kennedy, R. E. Mulvey, R. B. Rowlings, W. Clegg, S. T. Liddle, C. C. Wilson, Chem. Commun. 2000, 1759; b) Y. Kondo, J. V. Morey, J. C. Morgan, H. Naka, D. Nobuto, P. R. Raithby, M. Uchiyama, A. E. H. Wheatley, J. Am. Chem. Soc. 2007, 129, 12734; c) D. R. Armstrong, E. Herd, D. V. Graham, E. Hevia, A. R. Kennedy, W. Clegg, L. Russo, Dalton Trans. 2008, 1323.

[25] R. E. Mulvey, Chem. Commun. 2001, 1049.

[26] D. Li, I. Keresztes, R. Hopson, P. G. Williard, Acc. Chem. Res. 2009, 42, 270.

[27] S. E. Baillie, W. Clegg, P. Garcia-Alvarez, E. Hevia, A. R. Kennedy, L. Russo, Chem. Commun. 2011, 47, 388.

[28] a) D. V. Graham, E. Hevia, A. R. Kennedy, R. E. Mulvey, Organometallics 2006, 25, 3297; b) S. E. Baillie, W. Clegg, P. Garcia-Alvarez, E. Hevia, A. R. Kennedy, J. Klett, L. Russo, Organometallics 2012, 31, 5131.

[29] M. Westerhausen, B. Rademacher, W. Schwarz, S. Henkel, Z. Naturforsch. 1994, 49b, 199.

[30] M. Westerhausen, Z. Anorg. Allg. Chem. 1992, 618, 131.

[31] M. Westerhausen, B. Rademacher, W. Poll, J. Organomet. Chem. 1991, 421, 175.

[32] G. M. Sheldrick, Acta. Crystallogr. 2007, A64, 112.

[33] O. V. Dolomanov, L. J. Bourhis, R. J. Gildea, J. A. K. Howared, H. Puschmann, J. Appl. Crystallogr. 2009, 42, 339. 
Eur. J. Inorg. Chem. 2016 • ISSN 1099-0682

\section{SUPPORTING INFORMATION}

DOI: 10.1002/ejic.201601020

Title: Synthesis, Structure and Solution Studies on Mixed Aryl/Alkyl Lithium Zincates

Author(s): Andrew J. Roberts, Alan R. Kennedy, Ross McLellan, Stuart D. Robertson,* Eva Hevia* 


\section{EXPERIMENTAL}

\section{General Conditions}

All reactions were performed under a protective argon atmosphere using standard Schlenk techniques. Hexane and benzene were dried by heating to reflux over sodium and benzophenone and distilled under nitrogen prior to use. TMEDA and PMDETA were distilled over $\mathrm{CaH}_{2}$ prior to use. All NMR spectra were recorded on a Bruker DPX $400 \mathrm{MHz}$ spectrometer, operating at $400.13 \mathrm{MHz}$ for ${ }^{1} \mathrm{H}, 155.50 \mathrm{MHz}$ for ${ }^{7} \mathrm{Li}$ and $100.62 \mathrm{MHz}$ for ${ }^{13} \mathrm{C}$. All ${ }^{13} \mathrm{C}$ NMR spectra were proton decoupled.

Elemental analyses were performed using a Perkin Elmer 2400 elemental analyser.

$\mathrm{Zn}\left(\mathrm{CH}_{2} \mathrm{SiMe}_{3}\right)_{2}$ was prepared according to a literature procedure. ${ }^{\mathrm{S1}}$

\section{X-ray Crystallography}

Crystallographic data were collected at $123(2) \mathrm{K}$ on an Oxford Diffraction diffractometer with Mo Ka $(\lambda=0.71073 \AA)$ or Cu K $\alpha(\lambda=1.54180 \AA)$. Structures were solved using SHELXS- $97^{\mathrm{S2}}$ or OLEX $2,{ }^{\mathrm{S3}}$ while refinement was carried out on $\mathrm{F}^{2}$ against all independent reflections by the full matrix least-squares method using the SHELXL-97 program or by the GaussNewton algorithm using OLEX2. All nonhydrogen atoms were refined using anisotropic thermal parameters. Data for compound $\mathbf{1}$ was measured from a non-single sample, with the initial data collection using an incorrect and higher symmetry unit cell. At the end of data collection the correct triclinic cell was identified and the data processed within CrysalisPro to remove the contribution of the second diffracting entity. This gave an acceptable quality structure but one with a lower percentage completeness than normal ( $88 \%$ ). Recollection using other samples did not give suitable quality structures. Selected crystallographic and refinement details are given in Table S2.

CCDC 1499390 - 1499392 contain the supplementary crystallographic data for this paper. These data can be obtained free of charge from The Cambridge Crystallographic Data Centre (http://www.ccdc.cam.ac.uk/conts/retrieving.html)

\section{Synthesis of PhLi:}

To iodobenzene (1.78 mL, $16 \mathrm{mmol}$ ) in $30 \mathrm{~mL}$ hexane, "BuLi was added at room temperature dropwise yielding a yellow precipitate. The mixture was stirred at room temperature for 1 hour and filtered, rinsed with hexane, dried under vacuum and stored in a glovebox. Average yield $89 \%$.

Synthesis of $\left[\mathrm{Li}_{4} \mathrm{Zn}_{3} \mathrm{Ph}_{5}\left(\mathrm{CH}_{2} \mathrm{SiMe}_{3}\right)_{5}\right]_{\infty}$ (1): A Schlenk tube was charged with $\mathrm{Zn}\left(\mathrm{CH}_{2} \mathrm{SiMe}_{3}\right)_{2}(120 \mathrm{mg}$, $0.5 \mathrm{mmol}$ ) and PhLi (42 mg, $0.5 \mathrm{mmol}$ ) to which $5 \mathrm{~mL}$ benzene was added. This mixture was stirred at room temperature for 15 minutes, resulting in a colourless solution. Leaving this solution standing at room temperature resulted in the formation of colourless crystals (60 mg, $34 \%$ ). Due to the air sensitive nature of this compound no satisfactory elemental analyses could be obtained.

${ }^{1} \mathrm{H}$ NMR $\left(400.13 \mathrm{MHz}, 300 \mathrm{~K}, d_{8}\right.$-THF) $\delta(\mathrm{ppm})=-0.90\left(\mathrm{~s}, 2 \mathrm{H}, \mathrm{CH}_{2} \mathrm{Si}\left(\mathrm{CH}_{3}\right)_{3}\right)_{2},-0.08\left(\mathrm{~S}, 9 \mathrm{H}, \mathrm{CH}_{2} \mathrm{Si}(\mathrm{CH})_{3}\right)$, $6.80\left(\mathrm{t}, 1 \mathrm{H}, p-\mathrm{CH},{ }^{3} \mathrm{JHH}_{\mathrm{HH}}=7.64 \mathrm{~Hz}\right), 6.94\left(\mathrm{t}, 2 \mathrm{H}, m-\mathrm{CH}^{3}{ }^{3} \mathrm{HH}=7.20 \mathrm{~Hz}\right), 7.75\left(\mathrm{~d}, 2 \mathrm{H}, \mathrm{o}-\mathrm{CH}^{3}{ }^{3} \mathrm{HHH}=6.20 \mathrm{~Hz}\right)$

${ }^{13} \mathrm{C}\left\{{ }^{1} \mathrm{H}\right\}$ NMR $\left(100.62 \mathrm{MHz}, 300 \mathrm{~K}, d_{8}\right.$-THF) $\delta(p p m)=-2.0\left(\left(\mathrm{CH}_{2} \mathrm{Si}(\mathrm{CH})_{3}\right), 3.9\left(\mathrm{CH}_{2} \mathrm{Si}(\mathrm{CH})_{3}\right), 123.6(p-\mathrm{CH})\right.$, $125.7(m-\mathrm{CH}), 140.7(\mathrm{o}-\mathrm{CH})$

${ }^{7}$ Li NMR (298 K, $d_{8}-$ THF) $\delta(p p m):-0.54$ 


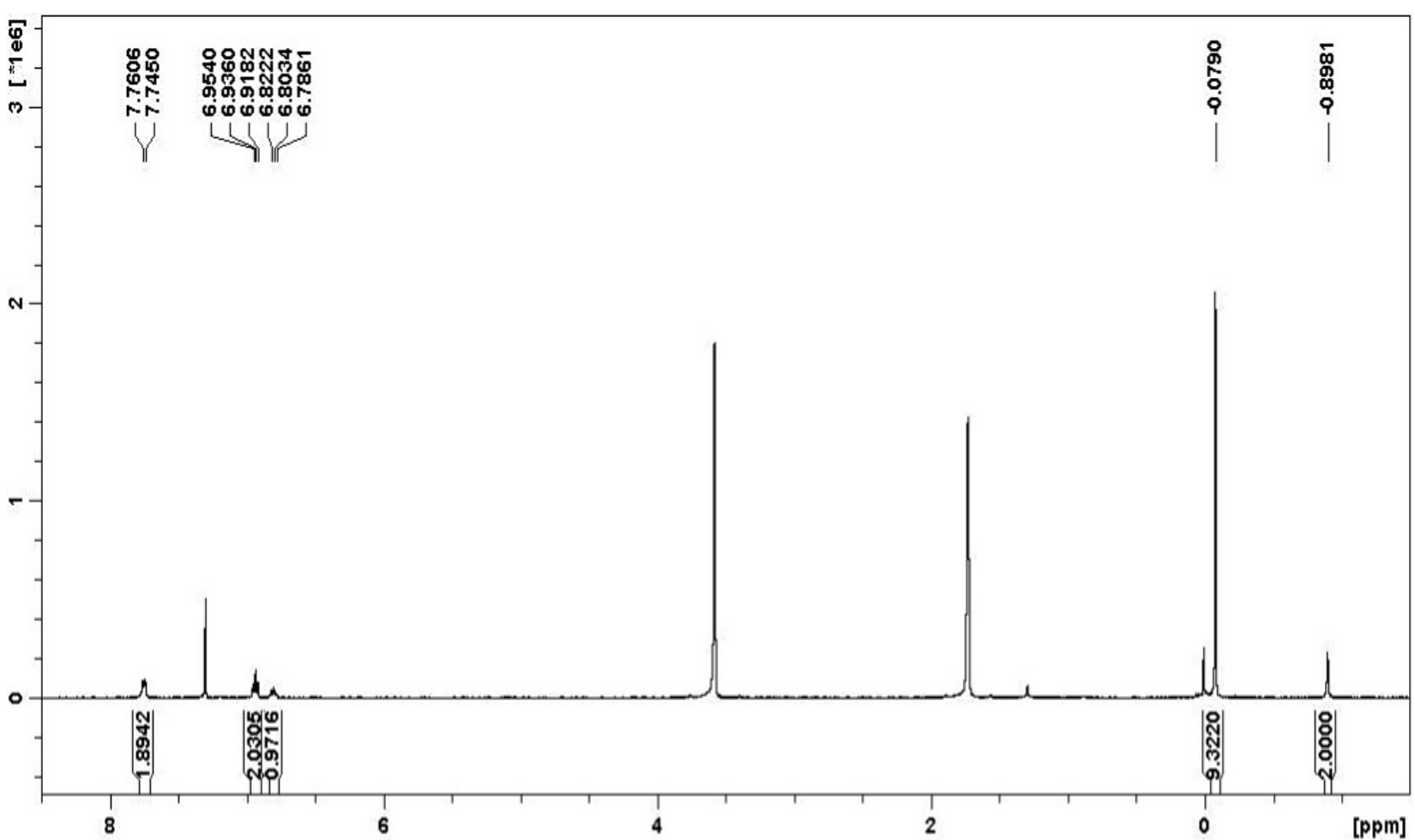

Figure S1: ${ }^{1} \mathrm{H}$ NMR spectrum of 1 recorded in $d_{8}$-THF

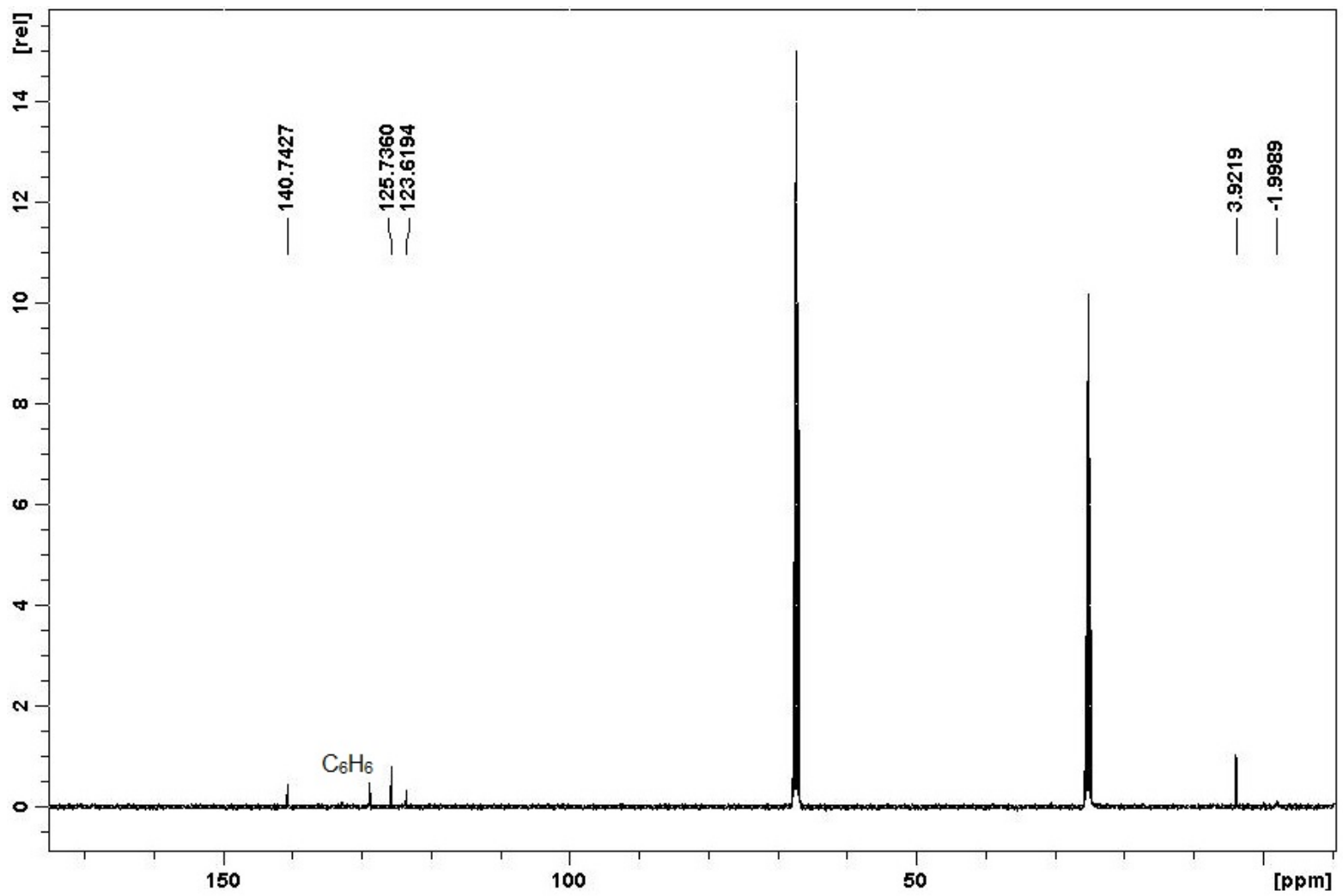

Figure S2: ${ }^{13} \mathrm{C}$ NMR spectrum of 1 recorded in $d_{8}$-THF 


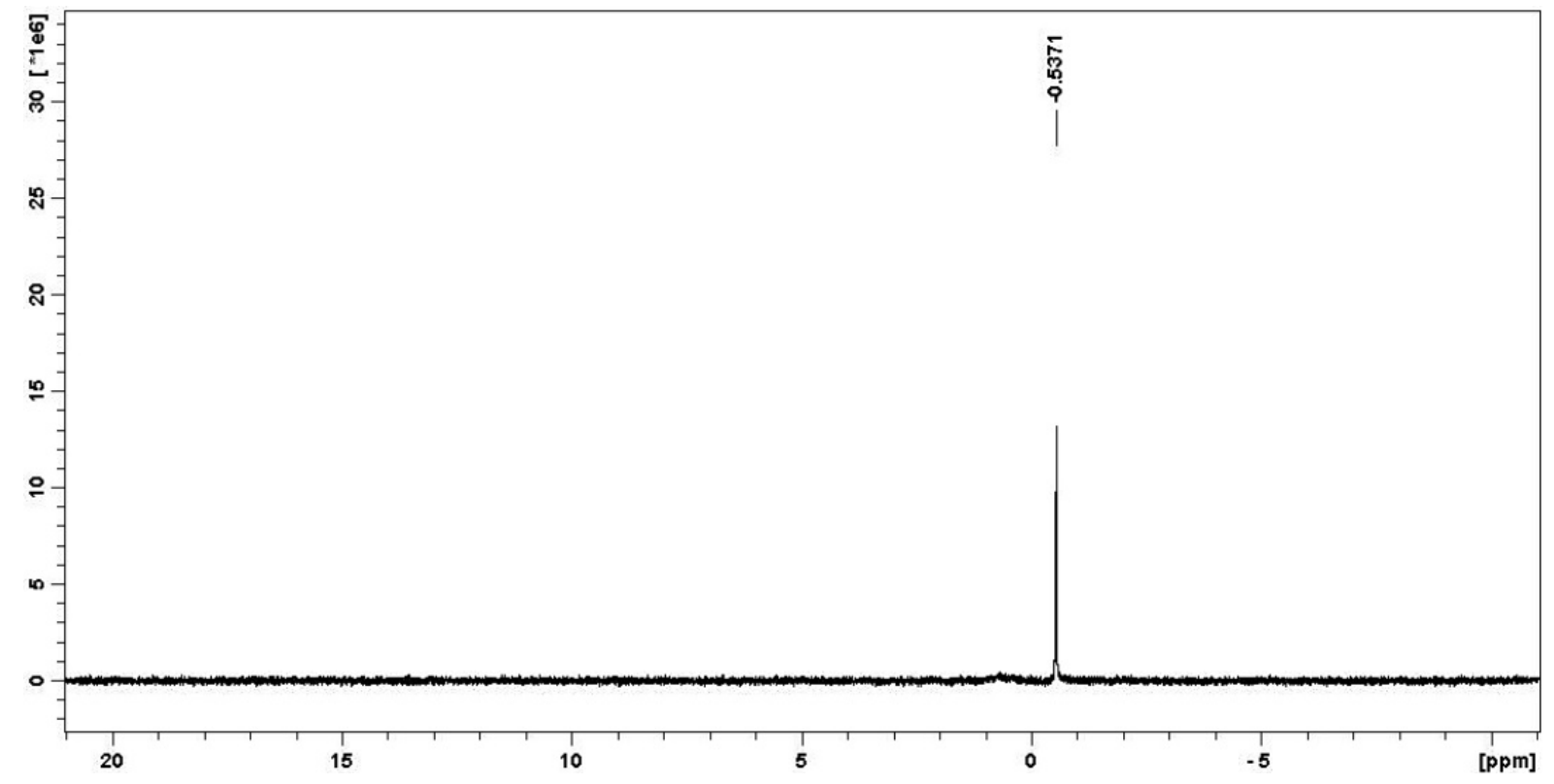

Figure S3: ${ }^{7}$ Li NMR spectrum of 1 recorded in $d_{8}$-THF

\section{Synthesis of [(PMDETA)LiZn $\left.\left(\mathrm{CH}_{2} \mathrm{SiMe}_{3}\right)_{2} \mathrm{Ph}\right](2)$}

A Schlenk tube was charged with $\mathrm{Zn}\left(\mathrm{CH}_{2} \mathrm{SiMe}_{3}\right)_{2}(120 \mathrm{mg}, 0.5 \mathrm{mmol})$ and PhLi $(42 \mathrm{mg}, 0.5 \mathrm{mmol})$ to which $5 \mathrm{~mL}$ hexane was added. To the resulting white suspension, PMDETA ( $0.11 \mathrm{~mL}, 0.5 \mathrm{mmol}$ ) was added. The resulting yellow solution was stirred for 15 minutes, resulting in a yellow oil from which crystal growth was possible upon cooling to $-35^{\circ} \mathrm{C}$. ( $84 \%$ crystalline yield)

${ }^{1} \mathrm{H}$ NMR $\left(400.13 \mathrm{MHz}, 300 \mathrm{~K}, \mathrm{C}_{6} \mathrm{D}_{6}\right) \delta(\mathrm{ppm})=-0.75$ (broad s, $\left.4 \mathrm{H}, \mathrm{CH}_{2} \mathrm{Si}\left(\mathrm{CH}_{3}\right)_{3}\right),-0.45(\mathrm{~s}, 18 \mathrm{H}$, $\left.\mathrm{CH}_{2} \mathrm{Si}\left(\mathrm{CH}_{3}\right)_{3}\right), 1.50\left(\mathrm{~s}, 3 \mathrm{H}, \mathrm{NCH}_{3}\right), 1.53-1.65\left(\mathrm{~m}, 8 \mathrm{H},-\mathrm{CH}_{2} \mathrm{CH}_{2}-\right), 1.83\left(\mathrm{~s}, 12 \mathrm{H}, \mathrm{N}\left(\mathrm{CH}_{3}\right)_{2}\right), 7.24$ (broad s, $1 \mathrm{H}, p-\mathrm{CH}$ ), 7.28 (broad s, $2 \mathrm{H}, m-\mathrm{CH}$ ), 8.15 (very broad s, $2 \mathrm{H}, o-\mathrm{CH}$ )

${ }^{13} \mathrm{C}\left\{{ }^{1} \mathrm{H}\right\}$ NMR $\left(100.62 \mathrm{MHz}, 300 \mathrm{~K}, \mathrm{C}_{6} \mathrm{D}_{6}\right) \delta(\mathrm{ppm})=0.7\left(\mathrm{CH}_{2} \mathrm{Si}\left(\mathrm{CH}_{3}\right)_{3}\right), 4.5\left(\mathrm{CH}_{2} \mathrm{Si}\left(\mathrm{CH}_{3}\right)_{3}\right), 44.5\left(\mathrm{NCH}_{3}\right)$, $45.9\left(\mathrm{~N}_{(}\left(\mathrm{CH}_{3}\right)_{2}\right), 53.1\left(-\mathrm{CH}_{2} \mathrm{CH}_{2}-\right), 57.0\left(-\mathrm{CH}_{2} \mathrm{CH}_{2}-\right), 125.7(p-\mathrm{CH}), 127.0(m-\mathrm{CH}), 140.8(o-\mathrm{CH})$. Cannot observe $\mathrm{i}-\mathrm{CH}$.

${ }^{7} \operatorname{Li~NMR}\left(298 \mathrm{~K}, \mathrm{C}_{6} \mathrm{D}_{6}\right) \delta(\mathrm{ppm}):-0.42$

Elemental analysis (\%) for $\mathrm{C}_{23} \mathrm{H}_{50} \mathrm{LiN}_{3} \mathrm{Si}_{2} \mathrm{Zn}$ : calcd: C 55.68, H 9.95, N 8.47; found C 55.31, H 9.78, N 8.84 


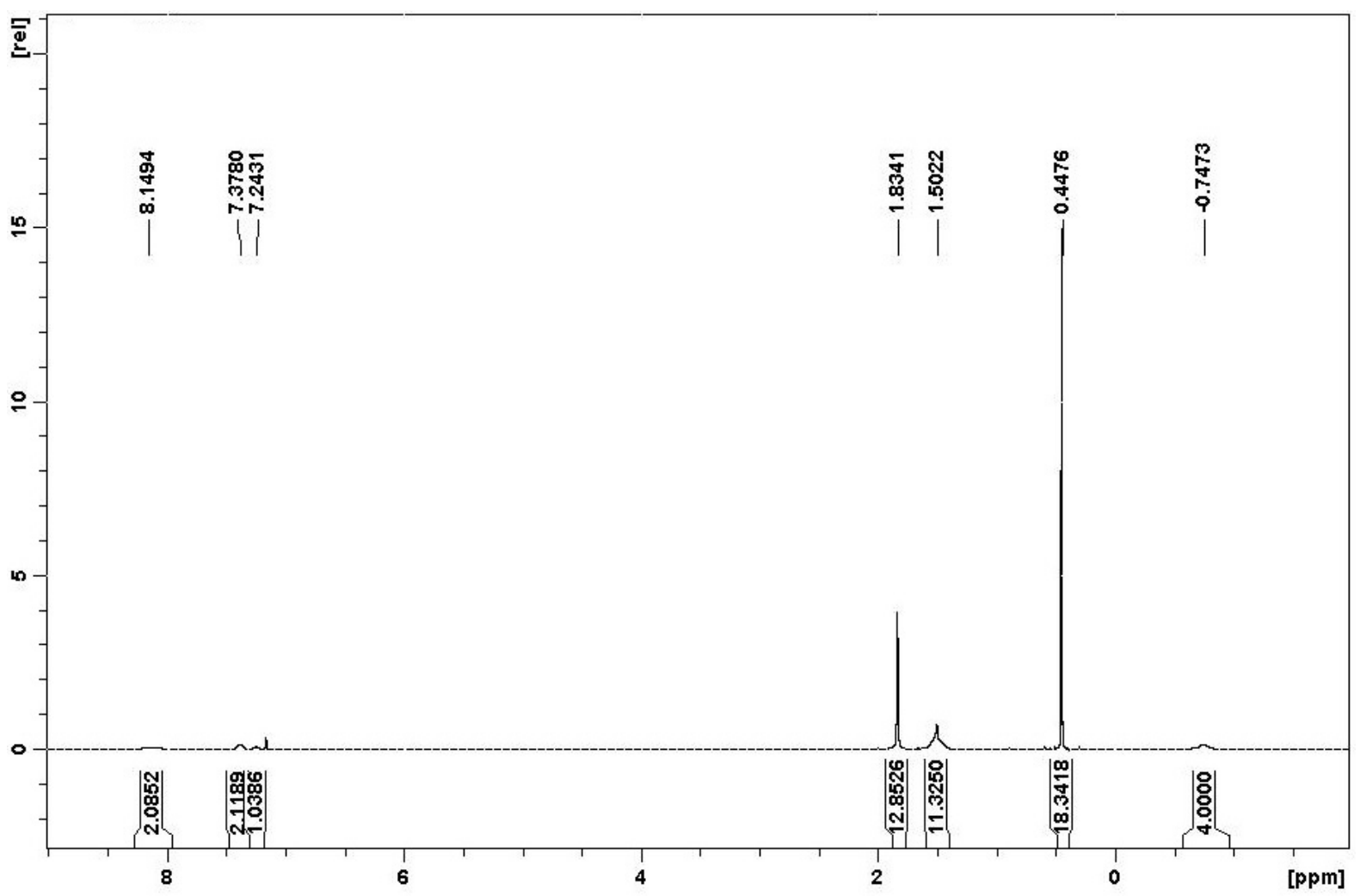

Figure S4: ${ }^{1} \mathrm{H}$ NMR spectrum of 2 recorded in $\mathrm{C}_{6} \mathrm{D}_{6}$

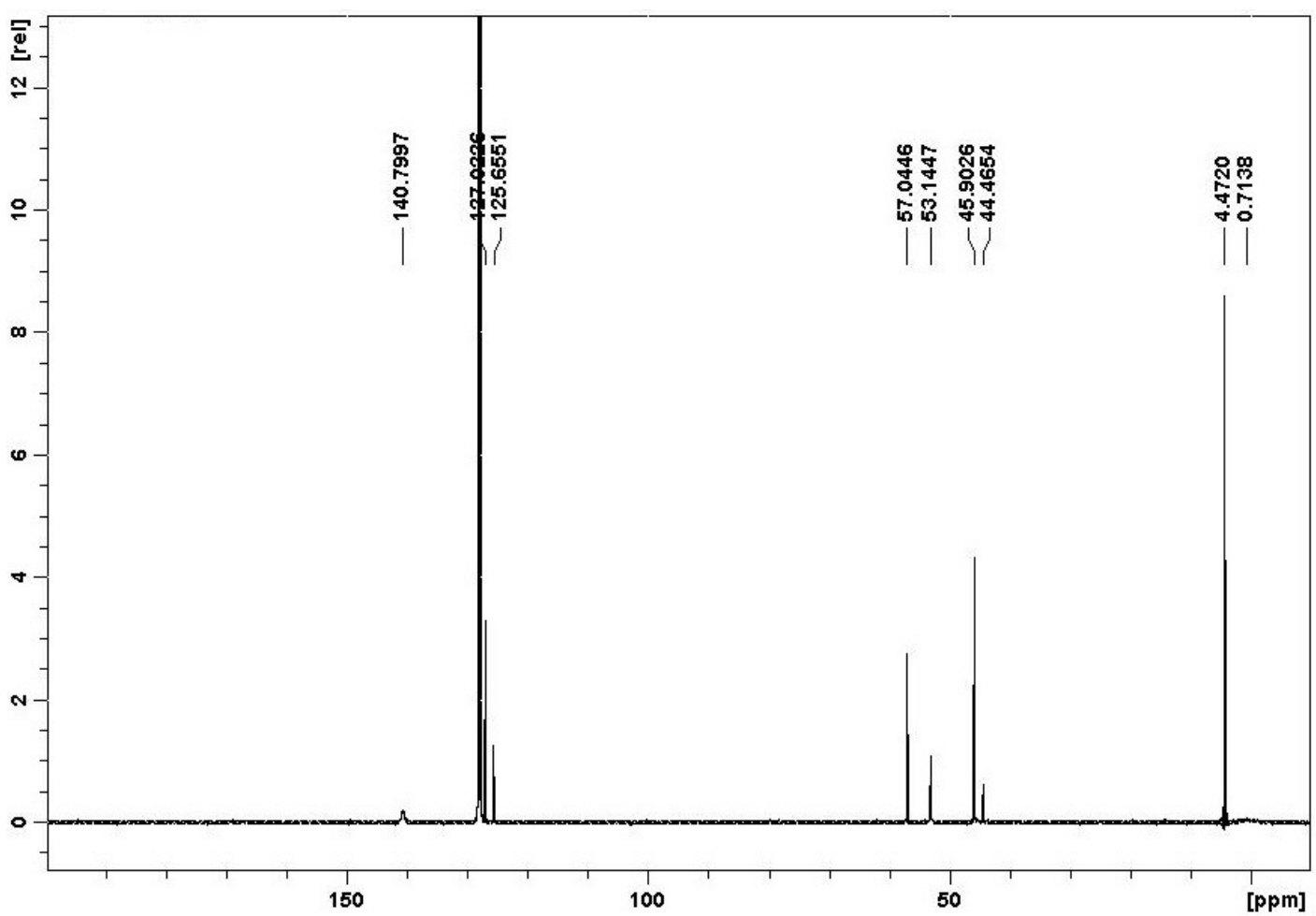

Figure S5: ${ }^{13} \mathrm{C}$ spectrum of 2 recorded in $\mathrm{C}_{6} \mathrm{D}_{6}$ 


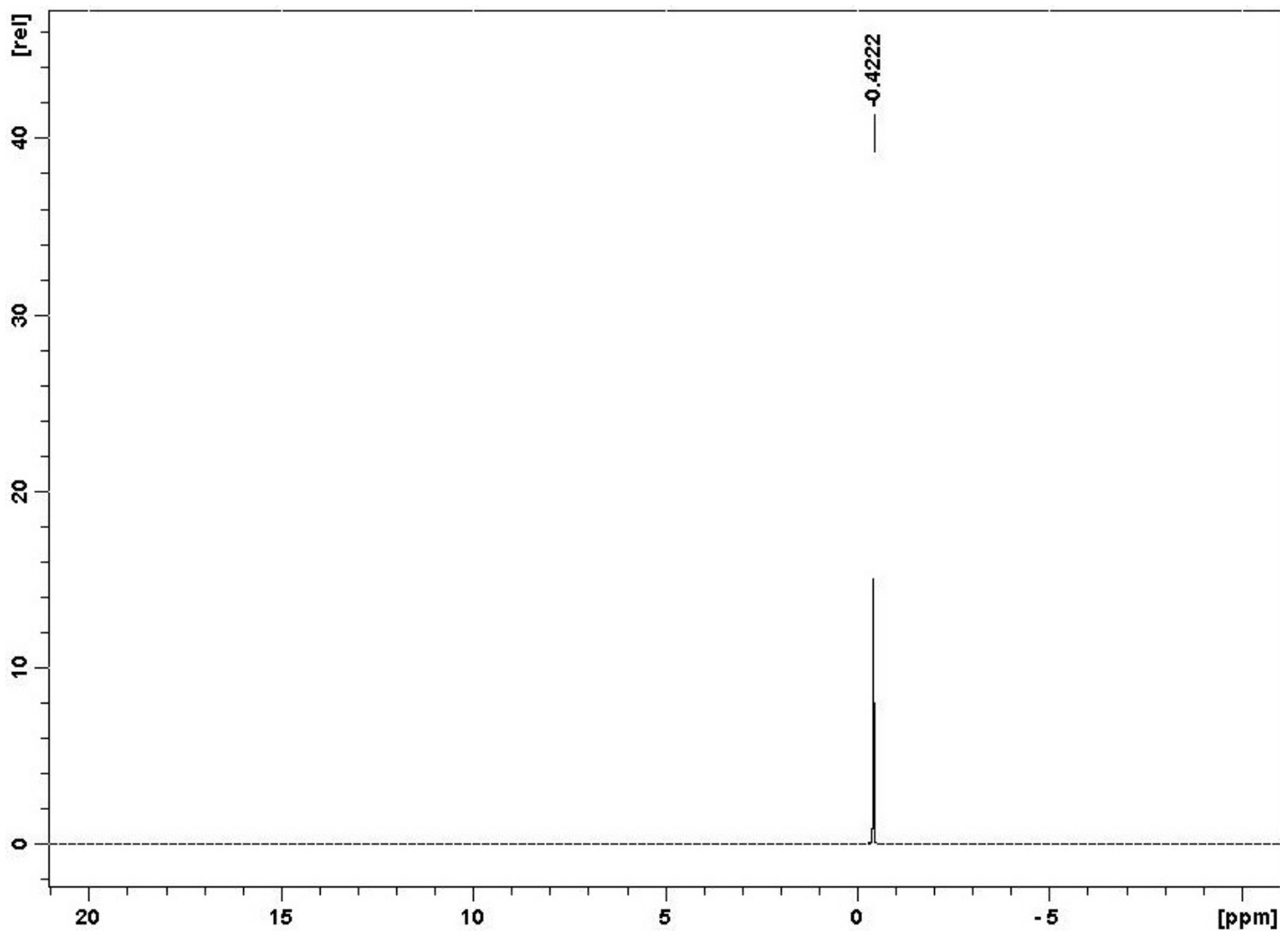

Figure S6: ${ }^{7} \mathrm{Li}$ NMR spectrum of 2 recored in $\mathrm{C}_{6} \mathrm{D}_{6}$

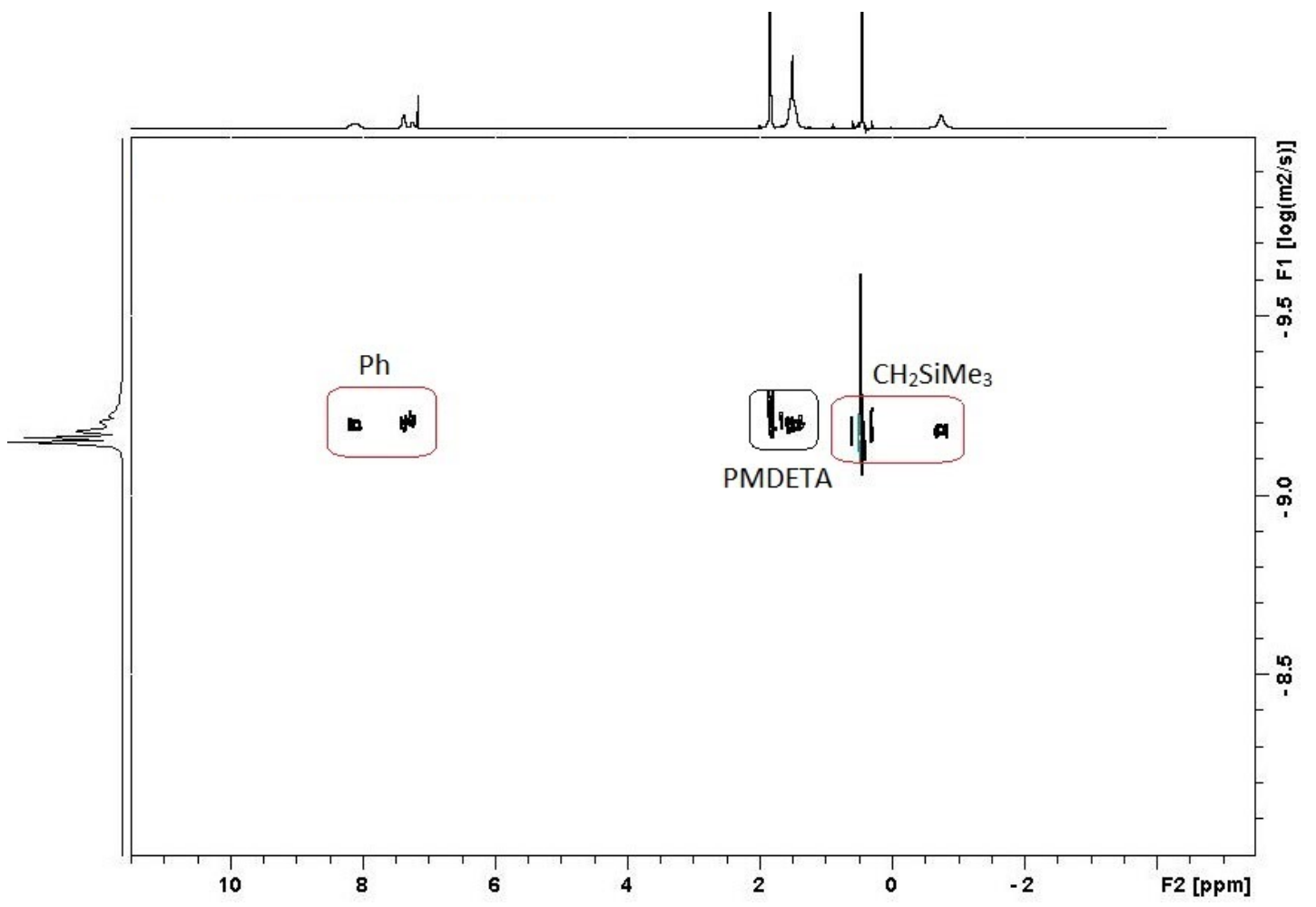

Figure S7: ${ }^{1} \mathrm{H}$ DOSY NMR spectrum of 2 recorded in $\mathrm{C}_{6} \mathrm{D}_{6}$ 


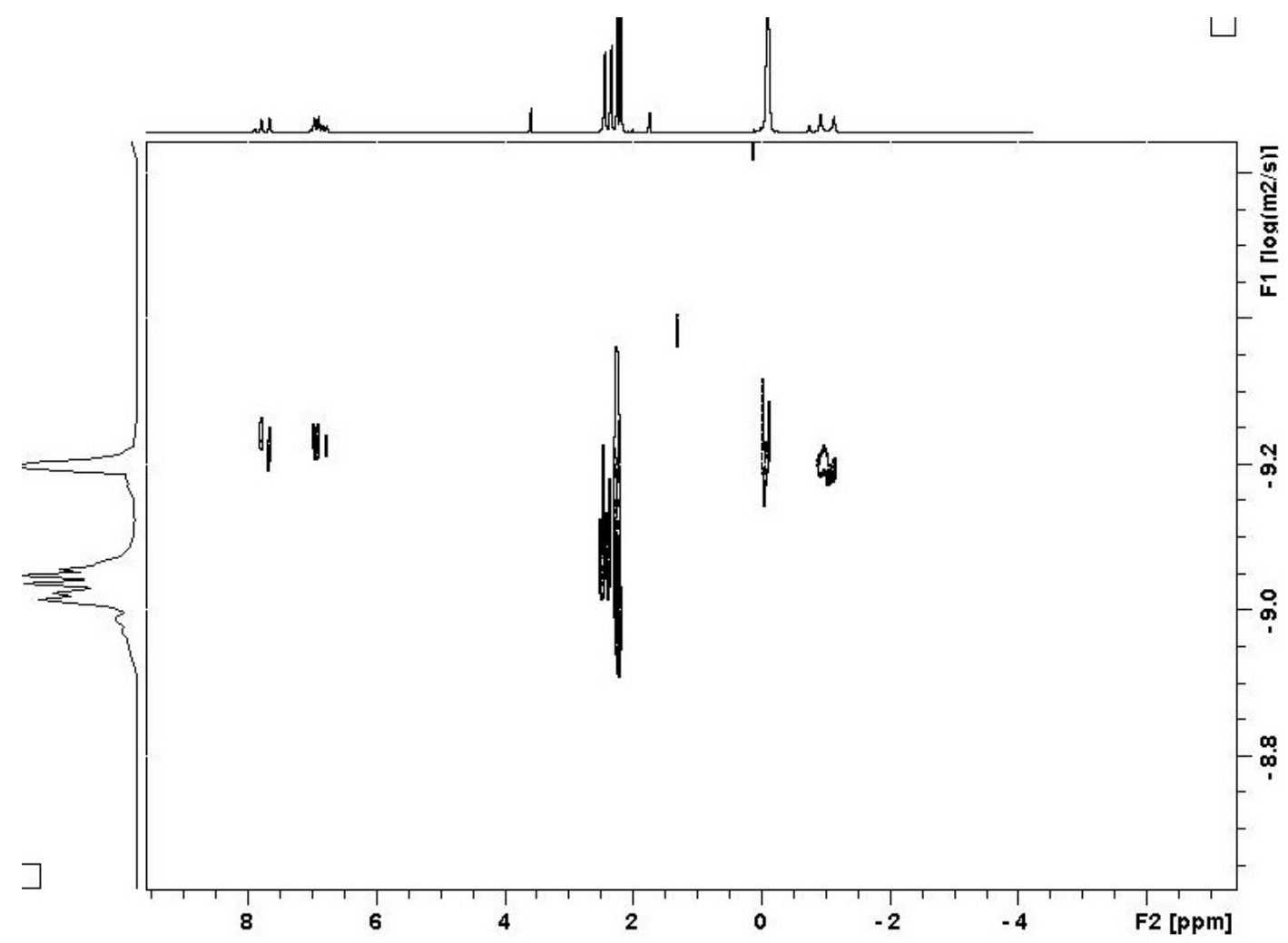

Figure S8: ${ }^{1} \mathrm{H}$ DOSY NMR spectrum of 2 recorded in $d^{8}-\mathrm{THF}$ at $273 \mathrm{~K}$

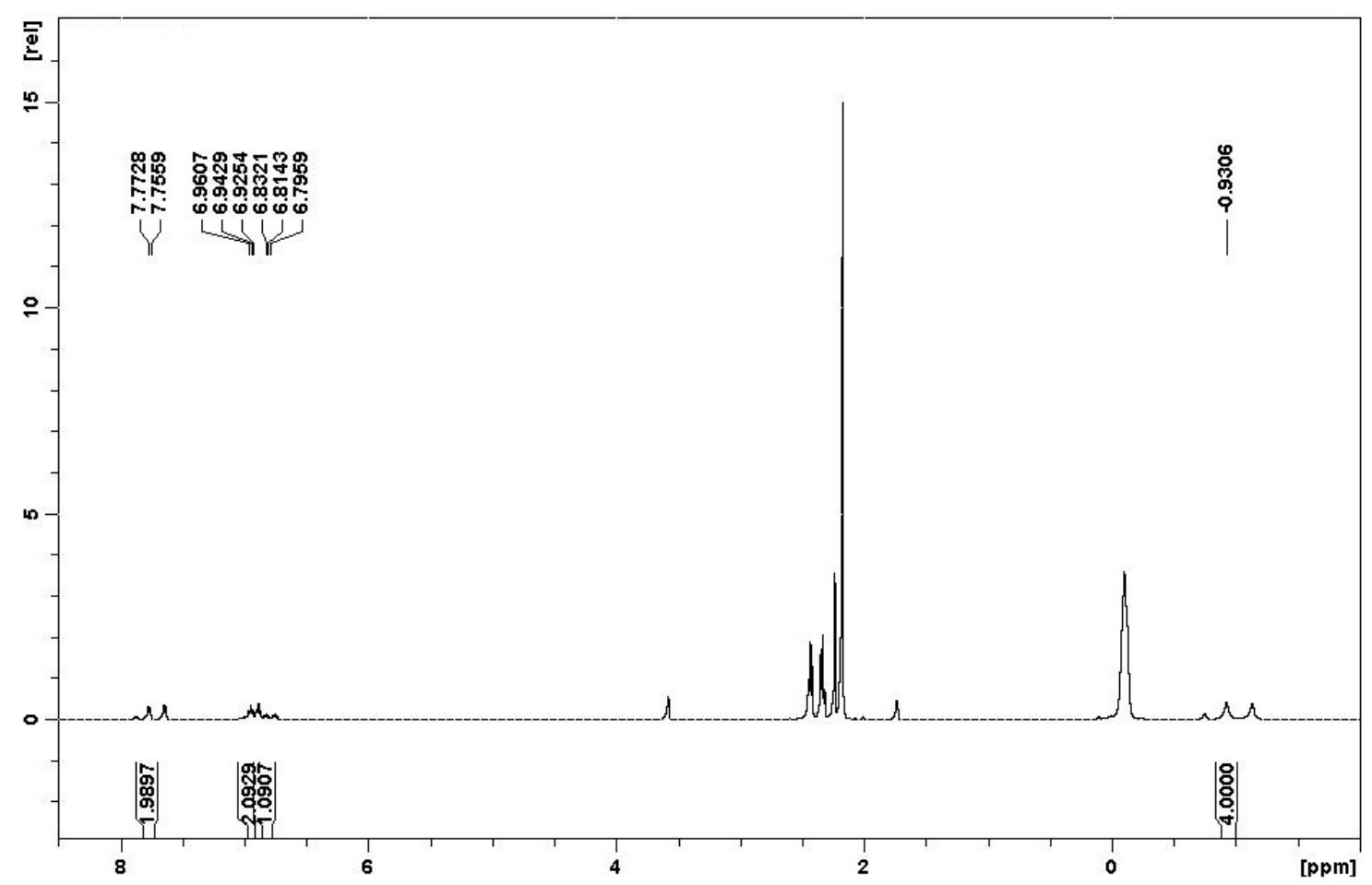

Figure 59: ${ }^{1} \mathrm{H}$ NMR spectrum of 2 in $d^{8}-\mathrm{THF}$ at $273 \mathrm{~K}$ showing resonances attributed to $\left[\mathrm{Zn}\left(\mathrm{CH}_{2} \mathrm{SiMe}\right)_{2} \mathrm{Ph}\right]^{-}$integrated 


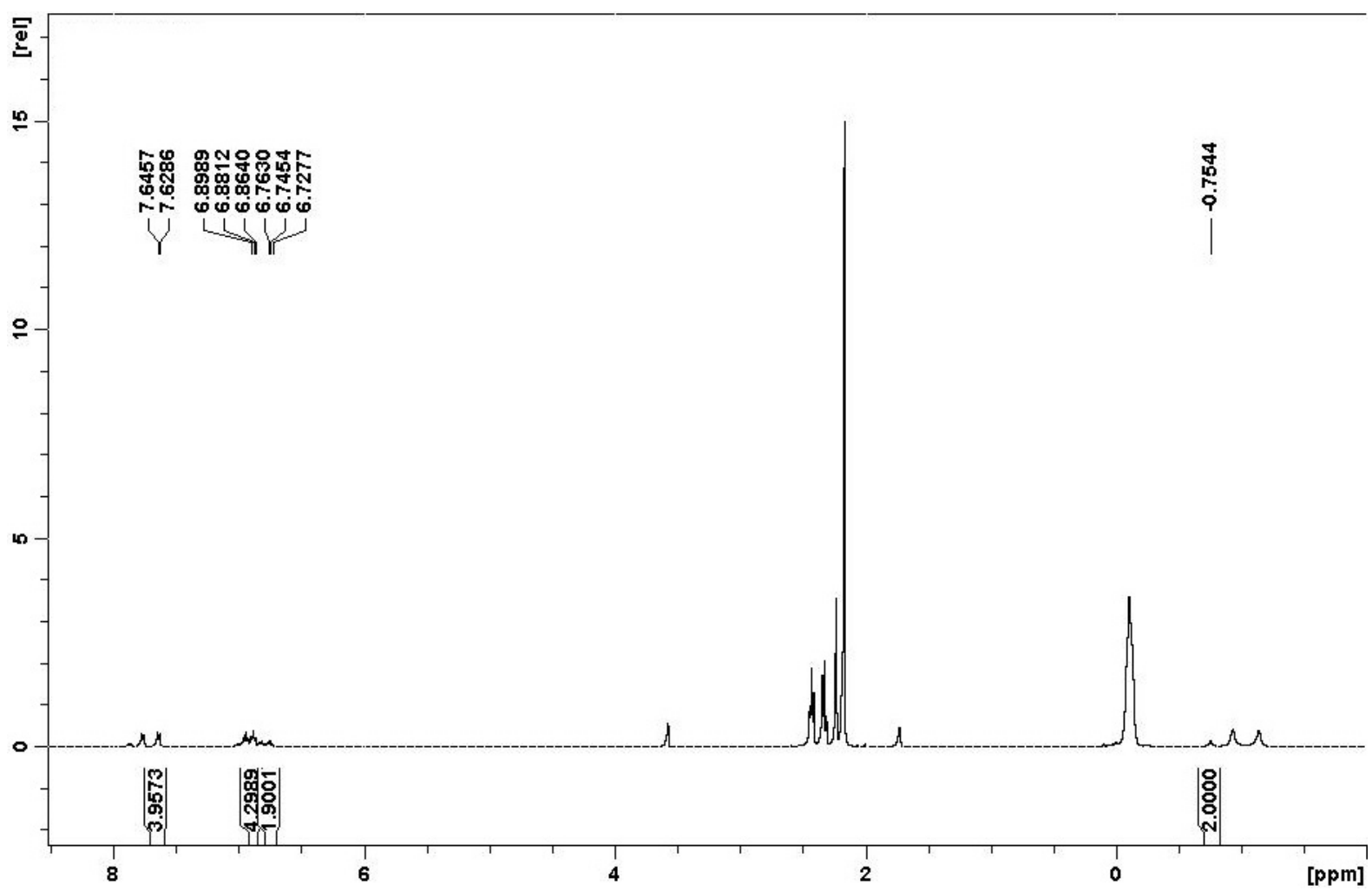

Figure S10: ${ }^{1} \mathrm{H}$ NMR spectrum of 2 in $d^{8}-\mathrm{THF}$ at $273 \mathrm{~K}$ showing resonances attributed to $\left[\mathrm{Zn}\left(\mathrm{CH}_{2} \mathrm{SiMe}_{3}\right) \mathrm{Ph}_{2}\right]^{-}$integrated

\section{Synthesis of [(TMEDA) $\left.\operatorname{LiZn}\left(\mathrm{CH}_{2} \mathrm{SiMe}_{3}\right)_{3}\right]$ (3)}

A Schlenk tube was charged with $\mathrm{Zn}\left(\mathrm{CH}_{2} \mathrm{SiMe}_{3}\right)_{2}(120 \mathrm{mg}, 0.5 \mathrm{mmol})$ and PhLi $(42 \mathrm{mg}, 0.5 \mathrm{mmol})$ to which $5 \mathrm{~mL}$ hexane was added. To the resulting white suspension, TMEDA (0.08 mL, $0.5 \mathrm{mmol}$ ) was added. The resulting yellow solution was stirred for 15 minutes, resulting in a yellow oil from which crystal growth was possible upon cooling to $-35^{\circ} \mathrm{C}$. (122 $\mathrm{mg}, 45 \%$ crystalline yield)

${ }^{1} \mathrm{H}$ NMR $\left(400.13 \mathrm{MHz}, 300 \mathrm{~K}, \mathrm{C}_{6} \mathrm{D}_{6}\right) \delta(\mathrm{ppm})=-0.90\left(\mathrm{~s}, 6 \mathrm{H}, \mathrm{CH}_{2} \mathrm{Si}(\mathrm{CH})_{3}\right), 0.40\left(\mathrm{~s}, 27 \mathrm{H}, \mathrm{CH}_{2} \mathrm{Si}(\mathrm{CH})_{3}\right), 1.47$ (bs, $4 \mathrm{H},-\mathrm{CH}_{2} \mathrm{CH}_{2}-$ ), 1.71 (bs, $12 \mathrm{H}, \mathrm{NCH}_{3}$ )

${ }^{13} \mathrm{C}\left\{{ }^{1} \mathrm{H}\right\}$ NMR $\left(100.62 \mathrm{MHz}, 300 \mathrm{~K}, \mathrm{C}_{6} \mathrm{D}_{6}\right) \delta(\mathrm{ppm})=1.9\left(\mathrm{CH}_{2} \mathrm{Si}(\mathrm{CH})_{3}\right), 4.2\left(\mathrm{CH}_{2} \mathrm{Si}(\mathrm{CH})_{3}\right), 45.6\left(\mathrm{NCH}_{3}\right), 56.4$ $\left(-\mathrm{CH}_{2} \mathrm{CH}_{2}-\right)$

${ }^{7}$ Li NMR $\left(298 \mathrm{~K}, \mathrm{C}_{6} \mathrm{D}_{6}\right) \delta(\mathrm{ppm}): 1.00$

Trace amounts of [(TMEDA) LiZn $\left(\mathrm{CH}_{2} \mathrm{SiMe}_{3}\right)_{2} \mathrm{Ph}$ ] were obtained during the formation of $\mathbf{3}$, leading to poor elemental analysis results 


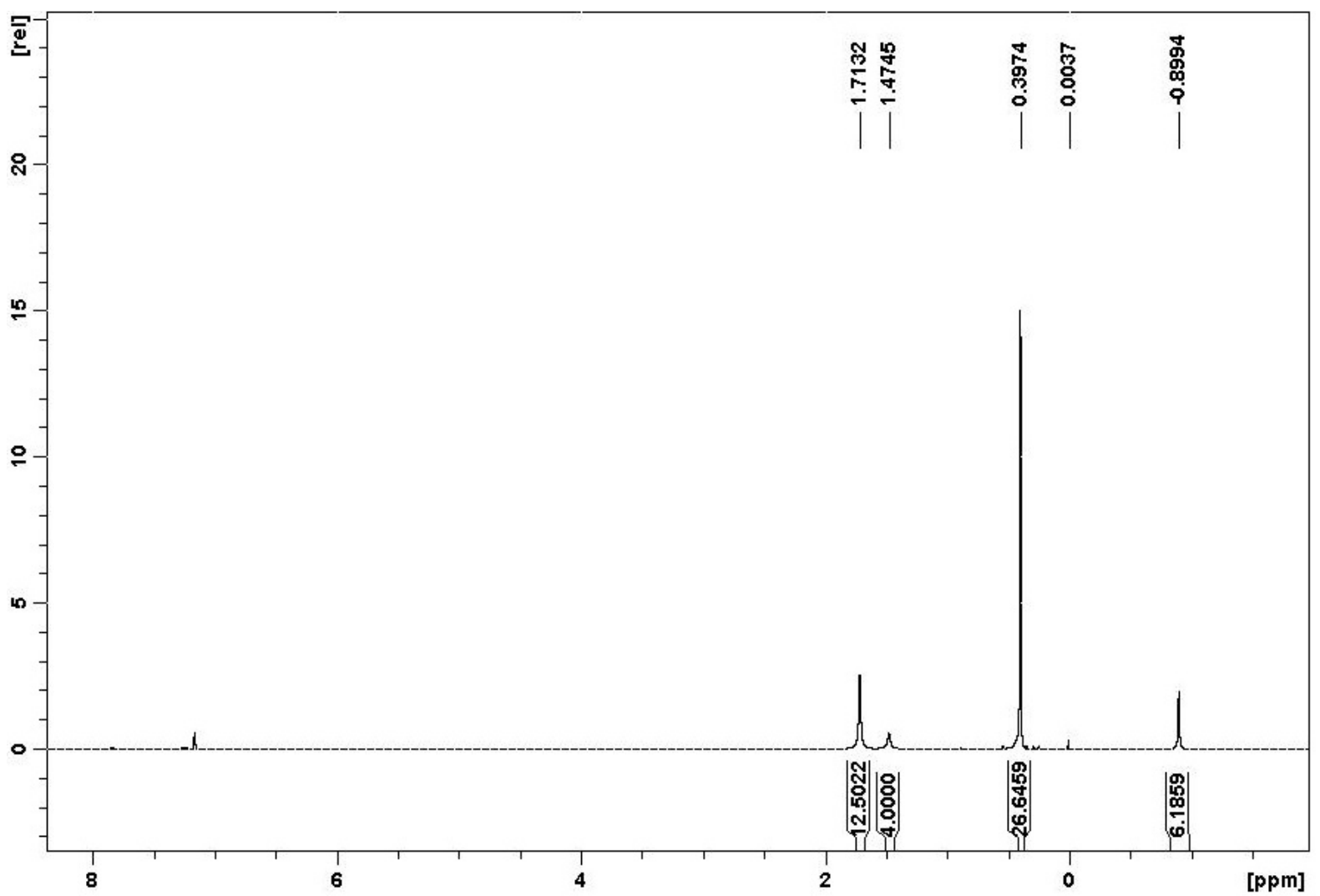

Figure S11: ${ }^{1} \mathrm{H}$ NMR spectrum of 3 recorded in $\mathrm{C}_{6} \mathrm{D}_{6}$

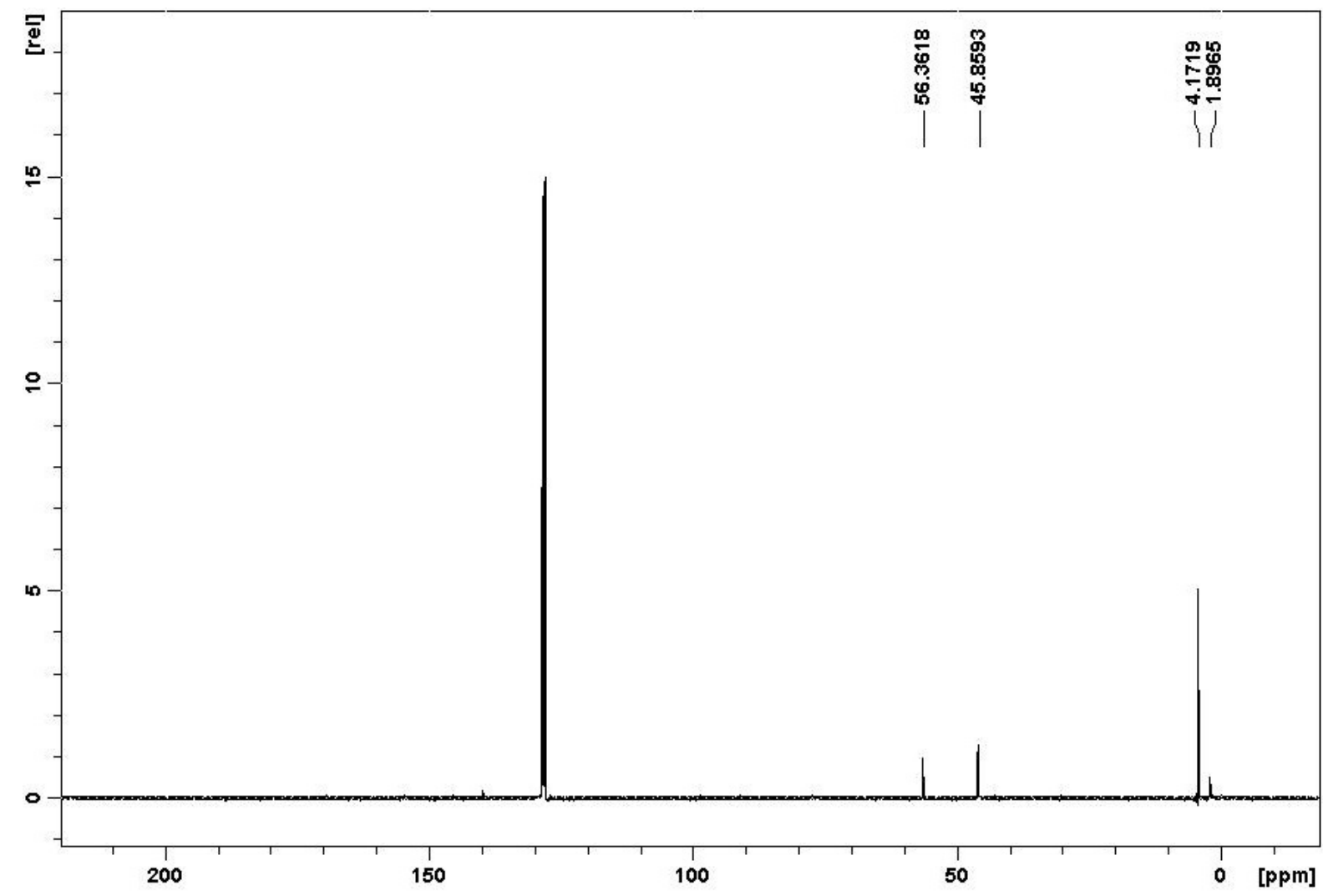

Figure S12: ${ }^{13} \mathrm{C}$ NMR spectrum of $\mathbf{3}$ recorded in $\mathrm{C}_{6} \mathrm{D}_{6}$ 


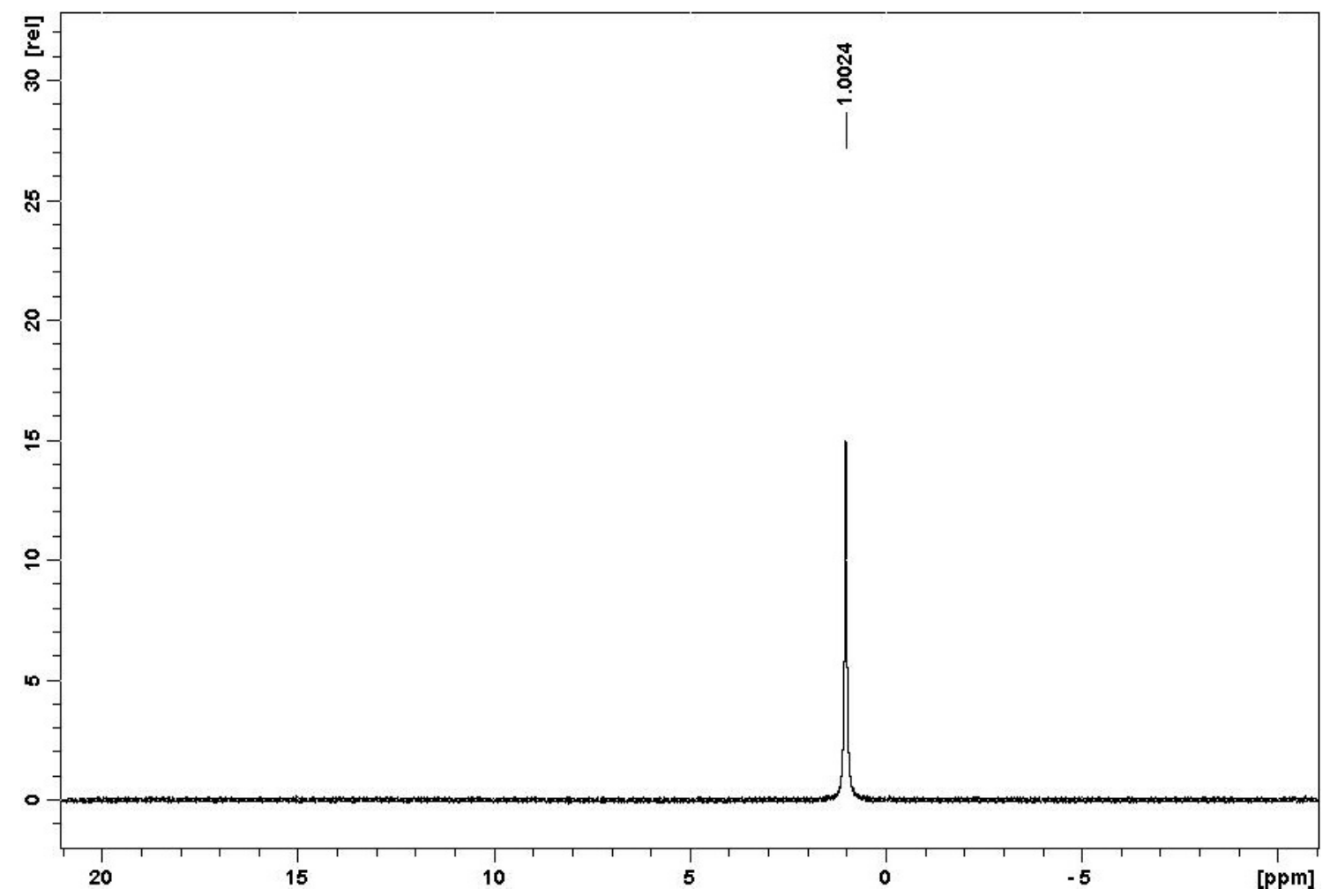

Figure S13: ${ }^{7}$ Li NMR spectrum of 3 recorded in $\mathrm{C}_{6} \mathrm{D}_{6}$

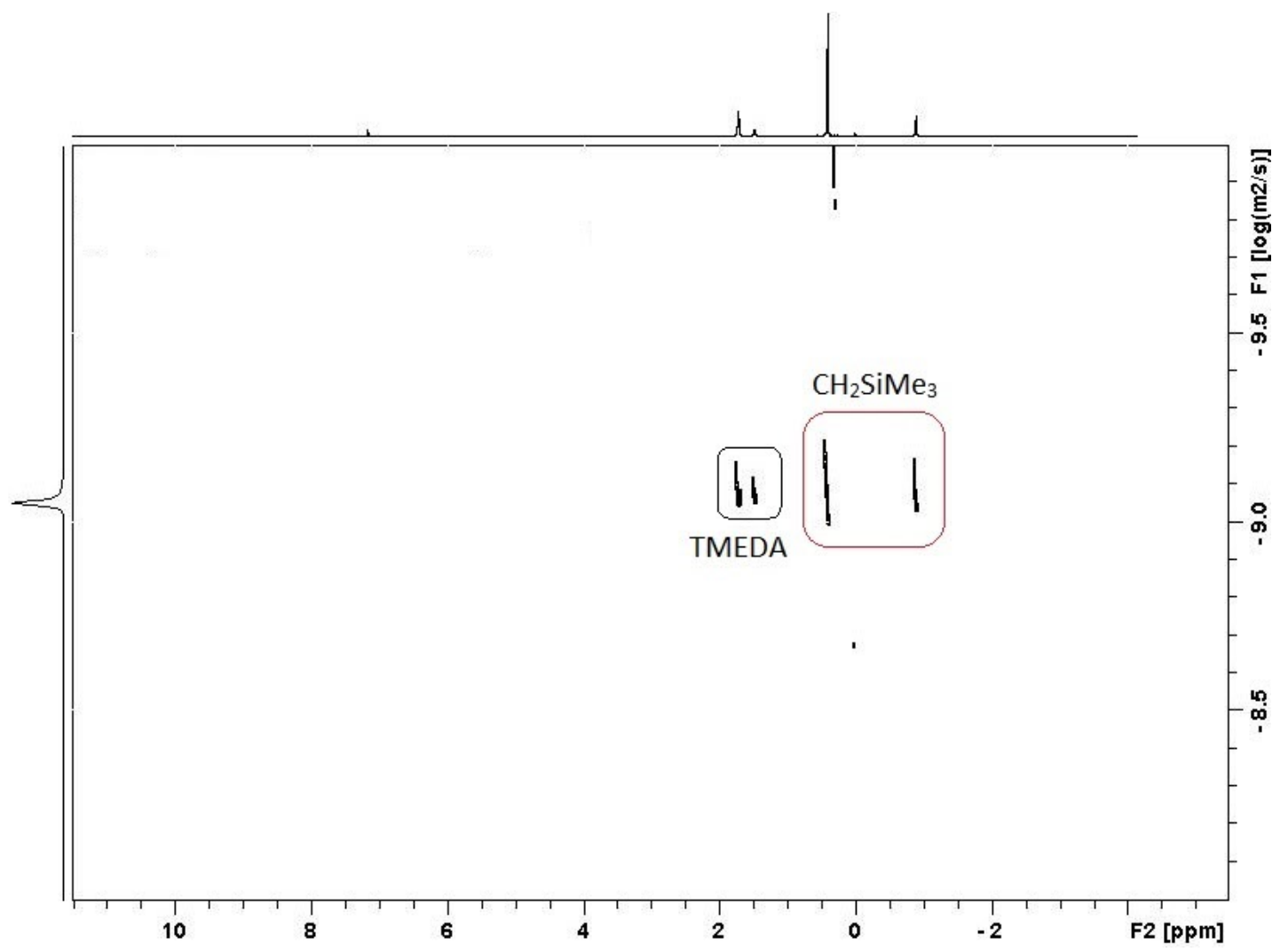

Figure S14: ${ }^{1} \mathrm{H}$ DOSY NMR spectrum of 3 recorded in $\mathrm{C}_{6} \mathrm{D}_{6}$ 


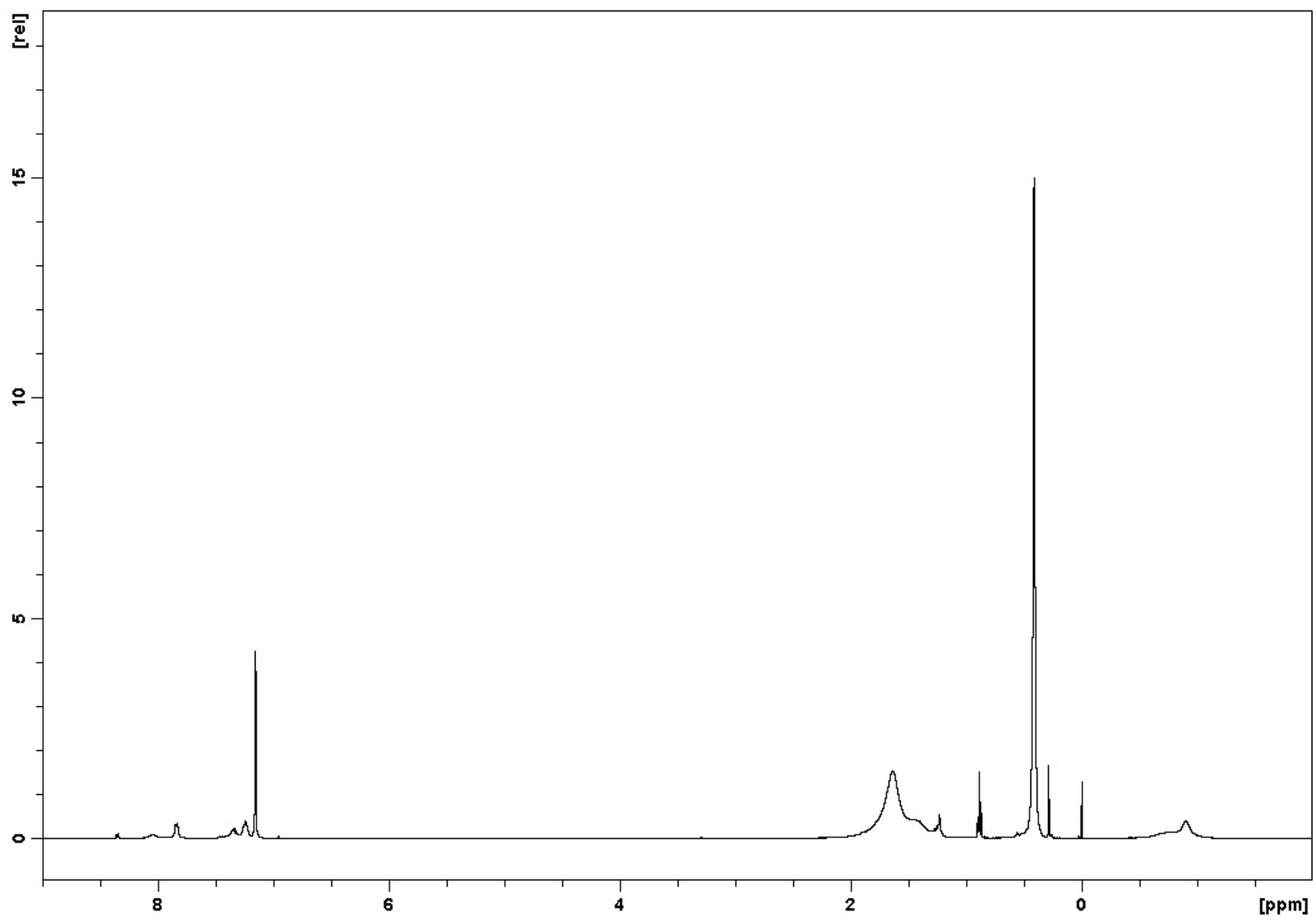

Figure S15: ${ }^{1} \mathrm{H}$ NMR spectrum of a reaction aliquot of 3 recorded in $\mathrm{C}_{6} \mathrm{D}_{6}$

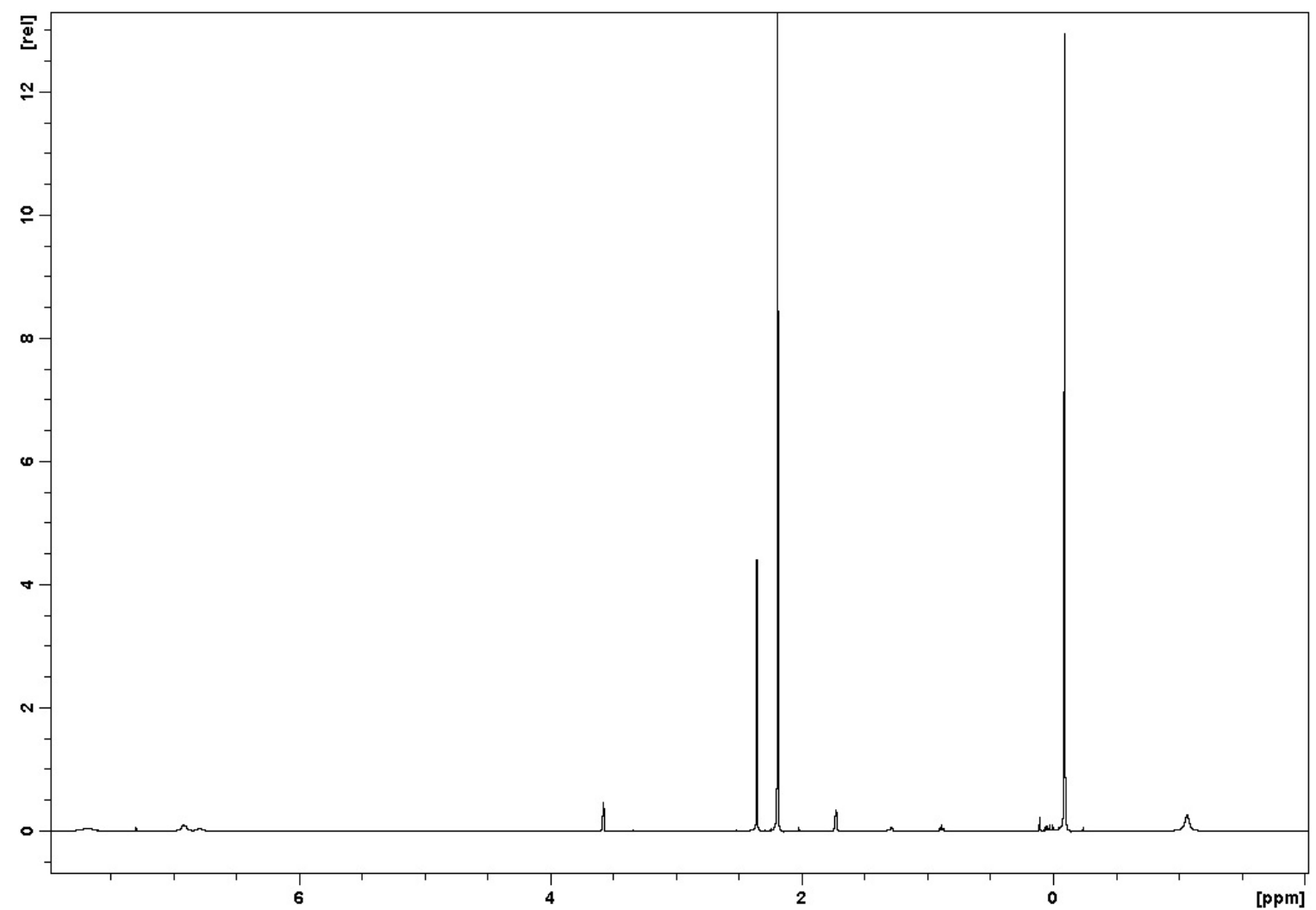

Figure S16: ${ }^{1} \mathrm{H}$ NMR spectrum of a reaction aliquot of 3 recorded in $d_{8}$-THF 


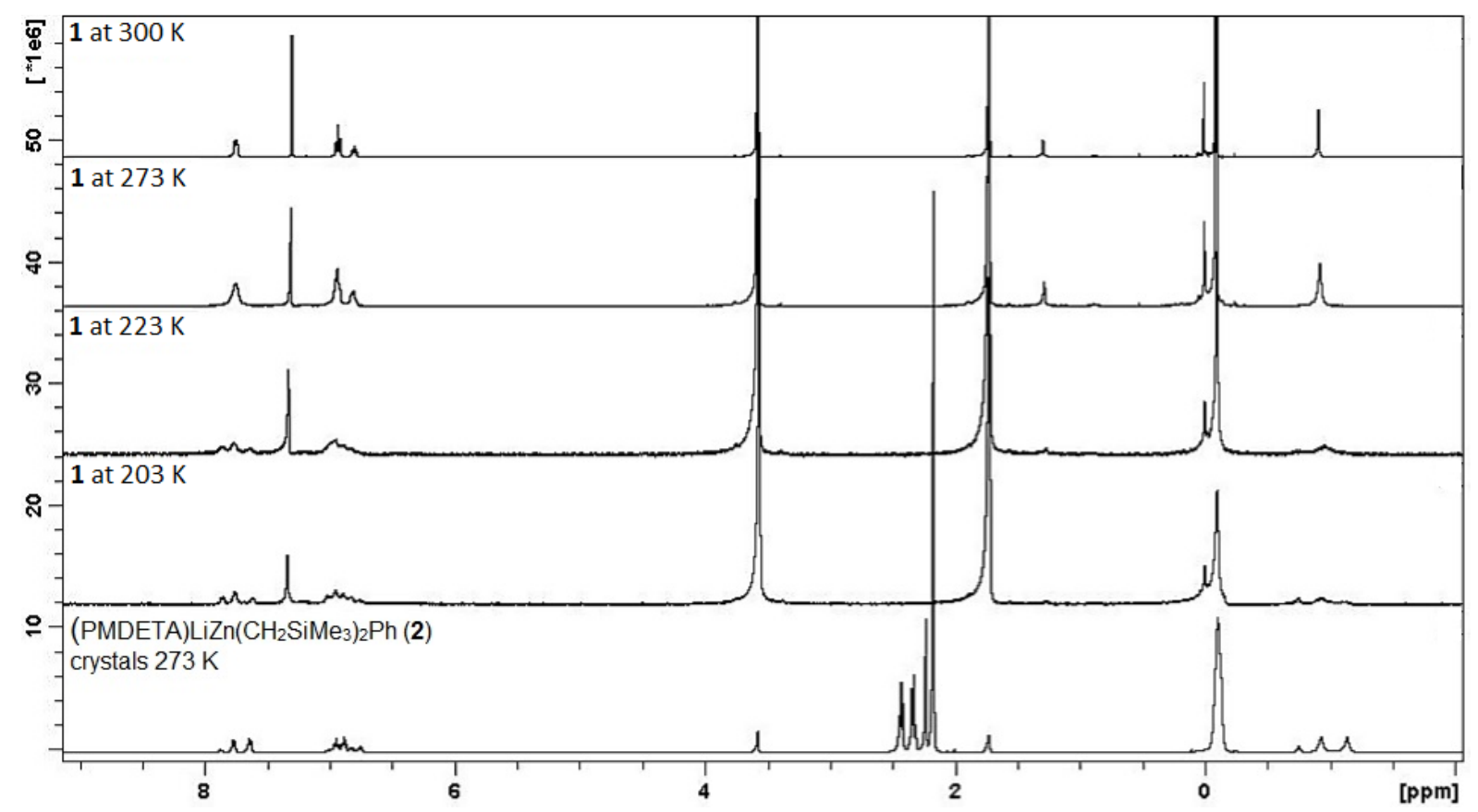

Figure S17: Overlay of variable temperature ${ }^{1} \mathrm{H}$ NMR spectra of 1 and $\mathbf{2}$ in $d_{8}$-THF

Table S1: Selected Bond Lengths $(\AA ̊)$ and Angles $\left({ }^{\circ}\right)$ for 1

\begin{tabular}{|l|l|l|l|}
\hline Zn2-C21 & $2.020(7)$ & C21-Zn2-C20 & $132.4(3)$ \\
\hline Zn2-C20 & $2.058(7)$ & C20-Zn2-C16 & $116.6(3)$ \\
\hline Zn2-C16 & $2.083(7)$ & C16-Zn2-C21 & $110.9(3)$ \\
\hline Li1-C12 & $2.3887(2)$ & C20-Li1-C12 & $109.1(6)$ \\
\hline Li1-C16 & $2.3676(3)$ & C16-Li1-C8 & $111.7(6)$ \\
\hline Li1-C8 & $2.4568(3)$ & C20-Li1-C16 & $99.6(6)$ \\
\hline Li1-C20 & $2.4388(2)$ & C12-Li1-C8 & $96.5(5)$ \\
\hline Zn1-C12 & $2.084(7)$ & C12-Zn1-C4 & $111.5(3)$ \\
\hline Zn1-C8 & $2.052(7)$ & C4-Zn1-C8 & $126.4(3)$ \\
\hline Zn1-C4 & $2.037(7)$ & C8-Zn1-C12 & $121.9(3)$ \\
\hline Li4-C39 & $2.300(14)$ & C4-Li4-C39 & $113.1(6)$ \\
\hline Li4-C33 & $2.299(15)$ & C39-Li4-C33 & $95.0(5)$ \\
\hline Li4-C34 & $2.787(15)$ & C33-Li4-C4 & $119.4(6)$ \\
\hline Li4-C38 & $2.8337(3)$ & C45-Zn3-C39 & $108.0(3)$ \\
\hline Li4-C4 & $2.2666(3)$ & C45-Zn3-C27 & $114.0(3)$ \\
\hline Zn3-C39 & $2.109(7)$ & C27-Zn3-C39 & $107.6(3)$ \\
\hline Zn3-C45 & $2.055(8)$ & C27-Zn3-C33 & $104.0(3)$ \\
\hline Zn3-C27 & $2.104(8)$ & & \\
\hline Zn3-C33 & $2.120(7)$ & & \\
\hline & & & \\
\hline
\end{tabular}


Table S2: Selected crystal data for 1, 2 and $\mathbf{3}$

\begin{tabular}{|c|c|c|c|}
\hline & 1 & 2 & 3 \\
\hline Empirical formula & $\mathrm{Zn}_{3} \mathrm{Li}_{4} \mathrm{Si}_{5} \mathrm{C}_{53.5} \mathrm{H}_{84}$ & $\mathrm{C}_{23} \mathrm{H}_{50} \mathrm{LiN}_{3} \mathrm{Si}_{2} \mathrm{Zn}$ & $\mathrm{C}_{18} \mathrm{H}_{49} \mathrm{LiN}_{2} \mathrm{Si}_{3} \mathrm{Zn}$ \\
\hline Formula weight & 1091.52 & 495.16 & 450.17 \\
\hline Temperature/K & $123(2)$ & $123(2)$ & $123(2)$ \\
\hline Crystal system & triclinic & orthorhombic & monoclinic \\
\hline Space group & P-1 & Pna2 $2_{1}$ & $\mathrm{C} 2 / \mathrm{c}$ \\
\hline$a / \AA$ & $12.3801(14)$ & $17.4910(8)$ & $33.7047(17)$ \\
\hline $\mathrm{b} / \AA$ & $15.1336(14)$ & $10.3472(6)$ & $10.1364(5)$ \\
\hline$c / \AA$ & $18.2513(18)$ & $16.3859(8)$ & 17.1523(9) \\
\hline$\alpha /^{\circ}$ & $106.566(8)$ & 90 & 90 \\
\hline$\beta /^{\circ}$ & $103.817(9)$ & 90 & 103.020(5) \\
\hline$\gamma /{ }^{\circ}$ & $94.627(8)$ & 90 & 90 \\
\hline Volume $/ \AA^{3}$ & $3141.8(6)$ & $2965.6(3)$ & $5709.3(5)$ \\
\hline $\mathrm{Z}$ & 2 & 4 & 8 \\
\hline$\rho_{\text {calc }} \mathrm{g} / \mathrm{cm}^{3}$ & 1.154 & 1.1090 & 1.047 \\
\hline$\mu / \mathrm{mm}^{-1}$ & 2.458 & 0.922 & 0.991 \\
\hline$\lambda(\AA)$ & 1.54184 & 0.71073 & 0.71073 \\
\hline$F(000)$ & 1154.0 & 1074.1 & 1968.0 \\
\hline $2 \Theta$ range for data collection ${ }^{\circ}$ & 7.45 to 139.98 & 6.1 to 56.34 & 6.124 to 60.406 \\
\hline Index ranges & $\begin{array}{c}-13 \leq \mathrm{h} \leq 15 \\
-18 \leq \mathrm{k} \leq 17 \\
-17 \leq \mathrm{I} \leq 22\end{array}$ & $\begin{array}{l}-23 \leq \mathrm{h} \leq 22 \\
-13 \leq \mathrm{k} \leq 12 \\
-20 \leq \mathrm{I} \leq 21\end{array}$ & $\begin{array}{c}-46 \leq h \leq 44 \\
-14 \leq k \leq 14 \\
-23 \leq 1 \leq 24\end{array}$ \\
\hline Reflections collected & 24827 & 24669 & 29838 \\
\hline Independent reflections & $\begin{array}{c}10435 \\
{\left[R_{\text {int }}=0.1145\right]}\end{array}$ & $\begin{array}{c}6646 \\
{\left[R_{\text {int }}=0.0709\right]}\end{array}$ & $\begin{array}{c}7782 \\
{\left[R_{\text {int }}=0.0393\right]}\end{array}$ \\
\hline Goodness-of-fit on $\mathrm{F}^{2}$ & 0.914 & 1.027 & 1.033 \\
\hline Final $R$ indexes $[I>=2 \sigma(I)]$ & $\begin{aligned} R_{1} & =0.0762 \\
w R_{2} & =0.1742\end{aligned}$ & $\begin{array}{c}R_{1}=0.0463 \\
w R_{2}=0.0860\end{array}$ & $\begin{array}{c}R_{1}=0.0482 \\
w R_{2}=0.1034\end{array}$ \\
\hline Final $R$ indexes [all data] & $\begin{array}{c}R_{1}=0.1496 \\
w R_{2}=0.2001\end{array}$ & $\begin{array}{c}R_{1}=0.0712 \\
w R_{2}=0.0969\end{array}$ & $\begin{array}{c}R_{1}=0.0741 \\
w R_{2}=0.1162\end{array}$ \\
\hline Largest diff. peak/hole / e $\AA^{-3}$ & $0.83 /-0.44$ & $0.42 /-0.42$ & $0.87 /-0.45$ \\
\hline
\end{tabular}

\section{References:}

S1: M. Westerhausen, B. Rademacher and W. Poll, J. Organomet. Chem., 1991, 421, 175.

S2: G.M. Sheldrick, Acta Crystallogr., 2007, A64, 112.

S3: O. V. Dolomanov; L. J. Bourhis; R. J. Gildea; J. A. K. Howard; H. Puschmann, J. Appl. Crystallogr. 2009, 42, 339. 